\title{
Aging and age-related diseases: from mechanisms to therapeutic strategies
}

\author{
Zhe Li • Zhenkun Zhang $\cdot$ Yikun Ren · Yingying Wang $\cdot$ Jiarui Fang $\cdot$ \\ Han Yue $\cdot$ Shanshan Ma $\cdot$ Fangxia Guan (i)
}

Received: 1 October 2020/ Accepted: 1 January 2021 / Published online: 27 January 2021

(C) The Author(s), under exclusive licence to Springer Nature B.V. part of Springer Nature 2021

\begin{abstract}
Aging is a physiological process mediated by numerous biological and genetic pathways, which are directly linked to lifespan and are a driving force for all age-related diseases. Human life expectancy has greatly increased in the past few decades, but this has not been accompanied by a similar increase in their healthspan. At present, research on aging biology has focused on elucidating the biochemical and genetic pathways that contribute to aging over time. Several aging mechanisms have been identified, primarily including genomic instability, telomere shortening, and cellular senescence. Aging is a driving factor of various age-related diseases, including neurodegenerative diseases, cardiovascular diseases, cancer, immune system disorders, and musculoskeletal disorders. Efforts to find drugs that improve the healthspan by targeting the pathogenesis of aging have now
\end{abstract}

Z. Li $\cdot$ Z. Zhang $\cdot$ Y. Ren $\cdot$ Y. Wang $\cdot$

J. Fang · S. Ma $(\bowtie) \cdot$ F. Guan $(\bowtie)$

School of Life Sciences, Zhengzhou University,

Zhengzhou 450001, Henan, China

e-mail: mashanshan84@163.com

F. Guan

e-mail: guanfangxia@126.com

H. Yue

Stem Cell Research Center, Henan Provincial People's Hospital, Zhengzhou 450003, Henan, China

S. Ma · F. Guan

Institute of Neuroscience, Zhengzhou University,

Zhengzhou 450052, China become a hot topic in this field. In the present review, the status of aging research and the development of potential drugs for aging-related diseases, such as metformin, rapamycin, resveratrol, senolytics, as well as caloric restriction, are summarized. The feasibility, side effects, and future potential of these treatments are also discussed, which will provide a basis to develop novel anti-aging therapeutics for improving the healthspan and preventing aging-related diseases.

Keywords Aging $\cdot$ Hallmarks of aging $\cdot$ Age-related diseases $\cdot$ Anti-aging drugs

\section{Introduction}

Since the dawn of human civilization, the desire for immortality has been a common pursuit. Due to improvements in living conditions and the continuous development of medical technology, human lifespan has increased dramatically over the last century (Campisi et al. 2019). Aging is the irreversibly progressive decline of physiological function, which eventually leads to age-related diseases, such as cardiovascular diseases, musculoskeletal disorders and arthritis, neurodegenerative diseases, and cancer. These age-related diseases produce a heavy economic and psychological burden for patients, their families, and society as a whole (de Magalhães et al. 2017). The 
primary feature of aging is the accumulation of cellular senescence (López-Otín et al. 2013) induced by destructive stimuli from inside and outside the cell (Hernandez-Segura et al. 2018). Cellular senescence affects the body in two ways. Firstly, excessive accumulation of senescent cells inevitably affects tissue regeneration. Secondly, senescent cells secrete a large number of inflammatory factors and present with the senescence-associated secretory phenotype (SASP), which has negative effects on the surrounding environment (López-Otín et al. 2013; Baker et al. 2016) found that although AP20187, a synthetic drug that activates FK506-binding protein-fused Casp8, effectively cleared senescent cells with high expression of p16 (Ink4a) and prolonged the lifespan of mice, some of the mice had elevated urea levels and exhibited severe thrombocytopenia (Baker et al. 2016). Bael et al. (2018) found that WM-1119, an inhibitor of the histone acetyltransferases KAT6A and KAT6B, could induce cellular senescence and arrest tumor growth in mice with lymphoma. Silva-Álvarez et al. (2020) found that the removal of senescent cells from adult zebrafish with limb amputation injuries was harmful to tissue regeneration (Da Silva-Álvarez et al. 2020). Thus, blocking cellular senescence may cause other complications. Therefore, cellular senescence is a double-edged sword when it comes to maintaining cellular balance.

Many strategies for ameliorating age-related diseases have been extensively studied, including calorie restriction through the control of diet and exercise and pharmaceutical treatments targeting specific cells and molecules (Di Daniele et al. 2017; Leong 2018). Although these treatments have achieved significant effects in various models, medication for the elderly is still a challenging issue that needs careful attention. This is because insufficient clinical data indicate that these drugs have a positive effect. On the other hand, careful consideration must also be given to the possible negative effects of these drugs. In this review, the mechanisms of aging will be described, several aging-related diseases will be identified to demonstrate the possible consequences of aging, and an analysis of the feasibility of targeted aging therapies will be performed to pave the way for future research on aging biology.

\section{Hallmarks of aging}

In order to illuminate the mechanisms and effects of anti-aging therapies on aging-related diseases, the cellular and molecular markers for aging must first be clarified. Based on the study of many different types of organisms, especially mammals, nine factors and related candidate markers are usually considered when determining the aging phenotype (López-Otín et al. 2013).

\section{Genomic instability}

One commonly accepted cause of aging is the accumulation of genetic damage, which could disrupt cell homeostasis and result in genome instability (Kubben and Misteli 2017). Somatic mutations, chromosomal aneuploidy, and copy mutations all contribute to exacerbating damage to the DNA (Tiwari and Wilson 2019). As humans age, defects appear in the DNA repair mechanism, which affects the expression of essential genes and the transcription pathways, leading to cell dysfunction. A large number of preclinical studies indicate that damaged DNA repair capability can lead to the occurrence of premature aging syndromes, such as Werner syndrome and Bloom syndrome (Foo et al. 2019). In addition, mutations in aged mitochondrial DNA and deficits in the nuclear lamina can also cause genome instability (Kauppila et al. 2018). Genome damage is closely related to aging, so interventions that can stabilize the genome and restore DNA repair capabilities should be explored to define its impact on aging.

Reduced telomere length

Telomeres are repetitive sequences at the distal ends of chromosomes. If telomeres reach a critically short length during cell division, known as the Hayflick limit, it triggers DNA damage and cellular senescence (Hayflick and Moorhead 1961; Herrmann et al. 2018). Importantly, telomere shortening also shows during natural aging in both humans and mice (Zhu et al. 2019). Also, numerous epidemiological studies have indicated that telomere depletion was significantly correlated to aging, biological morbidity, and mortality (Mensà et al. 2019). Telomerase, which is highly expressed in embryonic stem cells to extend telomeres, cannot be detected in most normal human cells 
(Saretzki 2018). Ullah et al. (2019) found that impaired telomerase activity accelerated senescence of stem cells (Ullah and Sun 2019). Jesus et al. (2012) reported that activation of telomerase activity through viral transduction could extend the survival time and reduce the incidence of cancer in wild-type mice (de Jesus et al. 2012). Notably, cells with short telomeres may escape senescence and become immortalized, usually by activating or upregulating telomerase. However, most human cancers have shorter telomeres and increased activity of telomerase (Shay 2016). Or it can be thought of in another way that the senescence caused by the shorter telomeres and limited telomerase activity may be the mechanism that prevents tumorigenesis in some large and long-lived mammals. There are several telomerase inhibitors in clinical phase II trials for the treatment of various cancers (Shay 2016). Telomere shortening can cause mammalian aging, while telomerase can reverse this phenomenon. Therefore, telomerase and its regulation of telomere length are important therapeutic targets for cancer and age-related diseases. Therefore, targeting telomeres or telomerase may be a strategy for developing innovative drug therapies to delay aging.

\section{Epigenetic alterations}

Modifications of chromatin include alterations in DNA methylation, histone modifications, and chromatin remodeling, which are related to cell aging (Kane and Sinclair 2019). Sirtuin families have been studied extensively as potential anti-aging factors. Ravi et al. (2019) reported that SIRT6 gene deletion severely affects cardiac function in mice and that inhibition of mTOR or Sp1 can eliminate the negative effects of SIRT6 gene deletion (Ravi et al. 2019). In addition, SIRT1 and SIRT3 genes all contribute to the improvement of healthy aging in mammals (Morigi et al. 2018). With aging, mammalian cells undergo global and local DNA hypomethylation (Kane and Sinclair 2019). Maierhofer et al. (2019) confirmed that DNA methylation and histone modifications were increased in mouse models of the premature aging syndrome (Maierhofer et al. 2019). However, there is still no evidence that DNA methylation can be changed to prolong life. It was shown that epigenetic changes could be reversed to some extent (Chen and Kerr 2019). Azacitidine and decitabine are epigenetic modifiers that have been approved by the FDA for treating myelodysplastic syndromes (MDS) and acute myeloid leukemia (AML). In clinical trials, both compounds have been shown to improve patients' pathology results while extending their average life expectancy (Kantarjian et al. 2012). Overall, understanding and manipulating the epigenome holds promise for improving age-related pathologies and extending a healthy lifespan.

\section{Loss of proteostasis}

The occurrence of aging and most aging-related diseases are related to the impairment of protein homeostasis. Protein aggregation, post-translational modification, and altered protein turnover are hallmarks of aging (Basisty et al. 2018). Autophagy and the ubiquitin-proteasome system are the primary protein degradation systems of the cells (Kaushik and Cuervo 2015; Klaips et al. 2018), and their activity declines with aging. Studies showed that the autophagy activators, such as rapamycin and spermidine, could extend the lifespan of yeast, nematodes, fruit flies, and mice (Wong et al. 2020). In addition, reducing protein synthesis by inhibiting the mTOR signaling pathway and calorie restriction also prolongs the lifespan (Basisty et al. 2018). Sorrentino et al. (2017) reported that maintaining protein homeostasis could reduce the aggregation of amyloid protein in Alzheimer's disease (AD) transgenic nematodes and mice and increased the lifespan of the test animals to a certain extent (Sorrentino et al. 2017). Collectively, studies on protein synthesis, quality control, and degradation pathways strongly suggest that maintenance of proteostasis is essential for health and longevity.

\section{Deregulated nutrient sensing}

Nutrient sensing through insulin/IGF-1 (IIS) was the first pathway demonstrated to regulate aging and agerelated diseases in organisms. Pharmacological or caloric restriction (CR) targeting nutrient signaling pathways have been shown to attenuate aging in many organisms (Santos et al. 2016). Attenuating the signaling activity of the IIS pathway consistently extended the lifespan (Mathew et al. 2017). Bitto et al. (2016) stated that transient rapamycin treatment could inhibit the mTOR signaling pathway, thereby extending the lifespan of middle-aged mice (Bitto et al. 
2016). Downregulation of mTORC1 expression also improved the average lifespan of yeast, elegans, and fruit flies (Arriola Apelo and Lamming 2016). The other two sensors in the IIS axis are AMPK and sirtuins. Emerging studies have demonstrated that metformin could activate the AMPK signaling pathway to extend the lifespan. Salminen et al. (2017) found that fibroblast growth factor 21 (FGF21) could extend the lifespan of mammals by activating AMPK signaling (Salminen et al. 2017). Studies also showed that CR could extend the lifespan of these model organisms by regulating the sirtuin family (Kapahi et al. 2017). Therefore, the synthesis and decomposition pathways of nutrient metabolism should be considered for targeted anti-aging therapies. Meanwhile, the complexity of certain signal pathways should also be deliberated. For example, the inhibition of mTOR will cause slow wound healing, insulin resistance, and other adverse reactions such as induced cataracts (Zaza et al. 2018).

\section{Cellular senescence}

Cellular senescence is a state of cell cycle arrest (Hernandez-Segura et al. 2018). The general view holds that aging is caused by a large accumulation of senescent cells in the tissue. The senescence-related secreted phenotype (SASP) and DNA damage are the main factors leading to senescence (Hernandez-Segura et al. 2017). In addition, mitochondrial dysfunction-associated senescence (MiDAS) is associated with mild or no transcriptional induction of several SASP factors (Wiley et al. 2016). For instance, inhibition of the IL-1 receptor reduced the expression of SASP and partially prevented oncogene-induced senescence (OIS) (Acosta et al. 2013). At the same time, many SASP factors exert non-cell-autonomous function and cause neighboring cells to age (Acosta et al. 2008; Ritschka et al. 2017). The critical role of $\mathrm{p} 16^{\mathrm{INK} 4 \mathrm{a}}$ and $\mathrm{p} 53$ in the induction of cell senescence has favored the hypothesis that they contribute to physiological aging (López-Otín et al. 2013). Cao et al. (2003) showed that the aging status of premature mutant mice can be significantly reduced by eliminating $\mathrm{p} 16^{\mathrm{INK} 4 \mathrm{a}}$ or $\mathrm{p} 53$, which was consistence with the findings of other groups (Baker et al. 2011; Cao et al. 2003). However, mice with a mild and systemic increase in $\mathrm{p} 16^{\mathrm{INK} 4 \mathrm{a}}, \mathrm{p} 19^{\mathrm{ARF}}$, or p53 tumor suppressors exhibited an extended lifespan (Matheu et al.
2007). However, it is worth noting that cellular senescence can also be beneficial. In fact, senescence is a potent anti-cancer mechanism that, as mentioned earlier, can prevent malignancy by limiting the replication of preneoplastic cells in the early stage. Several drugs, such as docetaxel, bleomycin, cyclophosphamide, doxorubicin, that are used in the clinical treatment of cancer are formally based on this feature of cellular aging known as therapy-induced senescence (TIS) (Calcinotto et al. 2019). In summary, cell senescence is a double-edged sword, which can either present a beneficial compensatory response to damage, or accelerate aging by exhausting tissue regeneration. Therefore, it is necessary to consider these two processes when developing new interventions.

\section{Stem cell exhaustion}

The loss of regenerative ability in tissues and organs is also one of the important features that cause aging. For example, with advancing age, the activity of hematopoietic stem cells decreases, which can lead to a series of pathological manifestations, such as a reduced adaptive immune response, an increased risk of anemia, and a decreased number of lymphoid cells (Goodell and Rando 2015). The same problem occurs in intestinal stem cells (ISCs). Compared with young mice, the number of ISCs in older mice is maintained at a lower level, resulting in a breakdown in intestinal structure and function (Keyes and Fuchs 2018). An important debate regarding the decline in stem cell function is the relative role of cell-intrinsic compared to cell-extrinsic pathways (Conboy and Rando 2012). Transplantation of muscle-derived stem cells from young mice to progeroid mice extended their lifespan and improved tissue function even though donor cells were not detected, suggesting that their therapeutic benefit may derive from systemic effects caused by secreted factors (Lavasani et al. 2012). Furthermore, using a parabiosis model, it has been demonstrated that the decline in neural and muscle stem cell function in old mice can be reversed by systemic factors from young mice (Xiong et al. 2018). Overall, targeting the senescence of stem cells has become a challenging problem that may provide novel concepts for therapeutic intervention. 
Mitochondrial dysfunction

Mitochondria dysfunction could cause a deficit in the respiratory chain, increased reactive oxygen species (ROS) production, reduced ATP levels (Green et al. 2011; Harman 1965), promote apoptosis and trigger inflammation, which causes a variety of age-related diseases. However, numerous studies have shown that increased mitochondrial ROS production and oxidative damage cannot reduce the lifespan of model organisms (Kauppila et al. 2017). This is because it is only when the ROS level exceeds a certain threshold that age-related damage is aggravated (Hekimi et al. 2011). Hood et al. (2019) pointed out that an imbalance in the mitochondrial network and impaired mitochondrial function will lead to an imbalance in the metabolic state of skeletal muscle and a decrease in muscle mass. Exercise can slow the aging process caused by mitochondrial imbalance (Hood et al. 2019). However, it is still uncertain whether improving mitochondrial function can delay aging and prevent or treat age-related diseases.

\section{Altered intercellular communication}

Cellular communication also plays an important role in the aging process by regulating neuroendocrine, endocrine, and neuronal levels (Diamanti-Kandarakis et al. 2017). Neurohormonal signalings (e.g., reninangiotensin, adrenergic, and insulin-IGF1 signaling) tend to mediate aging as inflammatory reactions increase, and the immunosurveillance environment changes (Salminen et al. 2012). Inflammation could be caused by the accumulation of proinflammatory cytokine secretion in senescent cells, an altered autophagy response, and increased NF- $\mathrm{KB}$ signaling (Green et al. 2011; Salminen et al. 2012; Senovilla et al. 2012). Genetic and pharmacological inhibition of $\mathrm{NF}-\kappa \mathrm{B}$ signaling could prevent age-related features in aging mouse models (Osorio et al. 2012). Inflammation and stress can activate the $\mathrm{NF}-\kappa \mathrm{B}$ signaling pathway in the hypothalamus, resulting in reduced GnRH. GnRH treatment can prevent impaired neurogenesis and slow down the aging process in mice (Zhang et al. 2013). Similar results also occurred in sirtuins. Pharmacological activation of SIRT1 may prevent inflammation in mice (Gillum et al. 2011). SIRT2 and SIRT6 also down-regulate inflammation through deacetylating NF- $\mathrm{BB}$ subunits and suppressing the downstream target genes (Kawahara et al. 2009; Yuan et al. 2016). In addition, cellular senescence influences neighboring cells via gapjunction contacts, growth factors, interleukins, and ROS, highlighting the importance of the microenvironment in modulating aging at different levels (Nelson et al. 2018). A large number of studies have shown that the change in intercellular communication is closely related to senescence. In a recent follow-up study, metformin significantly inhibited the expression of pro-inflammatory cytokines and reduced the associated risk of death in elderly diabetic patients (Tizazu et al. 2019). In primary hepatocytes, metformin inhibits TNF- $\alpha$-dependent NF- $\kappa \mathrm{B}$ signaling and the expression of IL- 6 and IL- $1 \beta$ by its unique anti-hyperglycemic mechanism (Cameron et al. 2016; Moiseeva et al. 2013). Resveratrol could also significantly reduce the peripheral secretion of inflammatory factors in patients with grade one hypertension by improving intercellular communication ( $\mathrm{Li}$ et al. 2018). As such, cellular senescence interferes with tissue homeostasis and regeneration and is responsible for aging-related diseases (van Deursen 2014). On the other hand, senescent cells can also play an active role in embryogenesis and tissue remodeling. For example, senescence is an effective barrier against tumorigenesis (Calcinotto et al. 2019). In the following, agerelated diseases associated with cellular senescence and the potential targets of anti-aging drugs, from a theoretical basis of the mechanisms behind agingrelated diseases, will be discussed.

\section{Age-related diseases}

Aging is the driving factor of various age-related diseases, and it causes a significant burden on social and economic stability. Based on the study of the Global Burden of Disease in 2017(GBD 2017), 92 of $293(31.4 \%)$ diseases were determined to be agerelated (Lublóy 2020). The most common agingrelated diseases included neurodegenerative diseases, cancer, cardiovascular diseases, and metabolic diseases.

Neurodegenerative diseases

Aging is the most common risk factor for the development of neurodegenerative diseases. 
Alzheimer's disease (AD) is the most common neurodegenerative disease in the world, and its incidence increases with advancing age (Trevisan et al. 2019). The characteristics of AD include extracellular amyloid plaques, intracellular neurofibrillary tangles (NFTs), and hyperphosphorylation of Tau protein (Xia et al. 2018; Janczura et al. 2018). Janczura et al. (2018) and Graff et al. (2012) found that histone acetylation was significantly reduced in the brains of AD patients and mice. Indirectly enhancing histone acetylation by chronic inhibition of histone deacetylases (HDACs) was able to reverse the cognitive deficits in a mouse model of AD (Kilgore et al. 2010). Aged mice and humans have a reduction in the number of neurons compared to their younger counterparts (Donev et al. 2009; Fabricius et al. 2013). Also, brain aging is mainly manifested by a large panel of pro-inflammatory factors characterized by SASP, altered signaling, and the accumulation of senescent glia (Harry 2013). The role of microglia in AD pathogenesis is complex (Wyss-Coray and Rogers 2012). Normally, microglia plays the role of a "scavenger", which is the main phagocytic cell in the brain, and performing a central role in the clearance of $A \beta$. However, the effectiveness of this clearance decreases with the development of AD (Njie et al. 2012; Olah et al. 2018) reported elderly microglia to have a more inflammatory phenotype (Olah et al. 2018). These findings showed that aged microglia presented both impaired neuroprotective abilities and low-grade neuroinflammation, but sustained secretion of the SASPs that drive inflammation in neurodegeneration. Additionally, reactive astrocytes are induced in various human neurodegenerative diseases, including AD (Liddelow and Barres 2017). Also, the number and the neurogenesis capability of neural stem cells (NSCs) decreases with age (Apple et al. 2017; Fan et al. 2017). Conversely, transplantation of NSCs slows the progression and restores spatial memory ability in AD mice (Zhang et al. 2017).

Parkinson's disease (PD) is also a neurodegenerative disease (Jankovic and Kapadia 2001). The prevalence of PD increases significantly, by approximately ten times, between 50 and 80 years of age (Pringsheim et al. 2014). The loss of dopaminergic neurons in the substantia nigra (SN) is considered a hallmark of PD (Kanaan et al. 2007). Several studies have shown that PD has the same cell function impairment seen in the aging process. The ubiquitin- proteasome system and lysosome in the brains of people with PD were mutated and showed histological signs of impaired function (Jankovic and Kapadia 2001). In addition, microglia cells showed increased staining intensity and transformation to activate phagocytic morphology during senescence, which occurs preferentially in the vulnerable vtSN region in PD. Compared to other sub-regions, the vtSN in elderly monkeys showed an excessively large microglia response, suggesting that the vtSN is more prone to neuroinflammation after being injured (Kanaan et al. 2008).

\section{Cardiovascular disease}

Aging has a significant effect on the heart and arterial system, leading to an increased prevalence of cardiovascular diseases (CVD), such as atherosclerosis, hypertension, myocardial infarction, and stroke (Donato et al. 2018). By 2030, about 20\% of the population will be over 65 years old, and CVD will cause $40 \%$ of all deaths (Heidenreich et al. 2011). Aging cardiovascular tissues demonstrate pathological alterations, including hypertrophy, altered left ventricular (LV) diastolic function, diminished LV systolic reserve capacity, increased arterial stiffness, and impaired endothelial function (Lakatta and Levy 2003). Telomere shortening is related to the occurrence of CVD, vascular cell aging, aortic valve stenosis, cardiovascular risk factors (i.e., hypertension, type 2 diabetes, obesity, and smoking), and arterial thrombotic events. However, the causality of these associations remains uncertain (Kurz et al. 2006). The age-dependent deficiency of adrenergic signal transduction and calcium treatment, which are associated with cell aging, can also cause incompetence and reduced muscle strength of the LV, and affects exercise endurance (Paneni et al. 2017). The age-dependent changes to mitochondrial adaptor p66 ${ }^{\text {Shc }}$ profoundly affect the steady-state of the cardiovascular system. Clinical studies have shown that p66 Shc expression is significantly increased in stroke patients (Spescha et al. 2013, 2015) also confirmed that the production of ROS in the brain of p66 Shc-deficient mice was reduced, and the size of stroke was reduced after ischemia-reperfusion brain injury (Spescha et al. 2013). Genome instability is also a risk factor for CVD. Hutchinson-Gilford progeria syndrome, characterized by massive nuclear DNA 
damage, is associated with premature atherosclerosis and CVD, which leads to fatal myocardial infarction (MI) or stroke by age 13 on average (Capell et al. 2007). In addition, abnormal epigenetic modifications also affect the incidence of CVD. SIRT6 can prevent endothelial dysfunction and atherosclerosis (Xu et al. 2016). SIRT1 overexpression improves the metabolic efficiency and endothelial function of aged mice (Winnik et al. 2015). The dysregulation of angiogenic pathways is associated with age-dependent reductions in the number and functionality of stem, and progenitor cells, including circulating angiogenic cells (CACs) and bone marrow (BM) derived cells (Lähteenvuo and Rosenzweig 2012).

\section{Cancer}

From 2010 to 2030, the aging of the US population will lead to a $67 \%$ increase in the incidence of cancer among Americans over 65 years of age (Smith et al. 2009). With the accumulation of senescent cells, the expression of SASP will increase and promote an inflammatory state, enhancing the invasive capabilities and accelerating the progression of cancer (Faget et al. 2019; Hartley et al. 2017). NF- $\kappa B$ and p38MAPK signaling pathways play important roles in the release of SASPs, which promote epithelial-mesenchymal transition (EMT) in cancer cells (Coppé et al. 2010). Epigenetic modification is an important link between aging and cancer. Aberrant methylation patterns are observed in almost all neoplasms. For example, $\mathrm{p} 21^{\mathrm{WAF} 1} / \mathrm{CIP} 1, \mathrm{p} 16^{\mathrm{INK} 4 \mathrm{a}}$, and the hypermethylation of these genes could drive carcinogenesis (Baylin and Ohm 2006; Li and Tollefsbol 2010). Fraga et al. (2005) found that cancer cells often exhibit losses in both histone acetylation and methylation, especially in $\mathrm{H} 4$ at the acetylated Lys16 and trimethylated Lys20 residues (Fraga et al. 2005). Histone acetyl dehydrogenase (HDAC) is closely related to the progression and prognosis of certain types of cancer, such as urogenital, reproductive, and gastrointestinal cancers (Li and Seto 2016). Histone deacetylase inhibitors (HDACi), such as MS-275 and SAHA, could trigger the apoptosis of advanced thyroid cancer by inhibiting HDAC1 and HDAC2 (Lin et al. 2019; Ma et al. 2019).
Immune system diseases

The immune system also undergoes dramatic agingrelated changes, which could cause the body to lose its ability to fight against infection and cancer and increase the risk of autoimmune diseases (Sadighi Akha 2018). The decline of the immune system is characterized by a shift in T-cell phenotype from native to memory, fewer early progenitor B cells, an increased proportion of mature T-cells, as well as chronic low-grade inflammation (Ray and Yung 2018). Naïve $\mathrm{CD}^{+} \mathrm{T}$ cells isolated from older humans and mice showed lower responsiveness to T-cell receptor stimulation and altered cytokine secretion profiles compared with Naïve CD4 ${ }^{+} \mathrm{T}$ cells isolated from young hosts. Also, the function of naïve $\mathrm{CD}^{+} \mathrm{T}$ cells to produce antibodies against B cells was reduced (Pereira et al. 2020; Raphael et al. 2020). However, age-dependent changes in the composition of memory $\mathrm{CD}^{+} \mathrm{T}$ cell subsets also imply a weakened immune response to viral infections (e.g., influenza virus and vaccines) (Gustafson et al. 2020). One of the hallmarks of age-related changes in the human immune system is the accumulation of CD28$\mathrm{CD}^{+} \mathrm{T}$ cells, which are absent in neonates and constitute the majority (80-90\%) of circulating CD8 ${ }^{+}$ $\mathrm{T}$ cells in the elderly. Accumulation of CD28$\mathrm{CD} 8+\mathrm{T}$ cells has also been found in viral infections such as COVID-19, which explains why the majority of patients with severe cases of COVID-19 are elderly (Pietrobon et al. 2020). In addition, naive CD4 $+\mathrm{T}$ cells had longer telomeres than memory CD4+T cells, and the difference in telomere length may reflect the number of cell divisions experienced by memory cells in vivo (Patrick and Weng 2019). Rufer et al. (1999) reported that telomere shortening was also found to occur during the transition from naïve to memory CD8 + T cells (Rufer et al. 1999). The aging lung is not only less functional, but it also has a reduced ability to prevent infections from environmental stresses and injuries. The aging of immune cells may lead to the development of disease. Th17 cells are predominantly observed in elderly asthmatics, in contrast to the Th2 inflammatory milieu presented in most young patients. Since Th17 cells can develop from the same lineage as anti-inflammatory regulatory $\mathrm{T}$ cells (Tregs), a preferential shift toward a Th17 response may reduce Tregs and promote the development of a pro-inflammatory environment in the elderly 
(Bullone and Lavoie 2017; Diller et al. 2016; Doe et al. 2010).

\section{Musculoskeletal disorders}

The elderly are prone to injuries and degenerative musculoskeletal disorders. Sarcopenia and osteoarthritis (OA) are among the most common aging-related musculoskeletal disorders and have a significant economic impact (Grote et al. 2019). Sarcopenia is defined as the loss of muscle mass and function with age. Skeletal muscle mass and function decline by $30-50 \%$ by age 80 , with the degree of muscle mass loss being worse in the elderly who are inactive. Increased inflammation leads to further ROS generation in skeletal muscles, which increases cell apoptosis and affects skeletal muscle catabolism (Musci et al. 2020). Impaired mitochondrial function and weakened antioxidant defenses have also been found to be associated with the development of sarcopenia (Gaffney et al. 2018). In addition, a growing number of studies have linked neuromuscular remodeling to muscle atrophy. Sheth et al. (2018) found that a decline in the number of motor units occurs before the loss of muscle function, which is due to reduced muscle size and contractility (Sheth et al. 2018). IL-6 inhibition is an approved and clinically effective therapy for rheumatoid arthritis (Favalli 2020). However, Costa et al. found that IL-6 knockout mice developed more severe symptoms of OA in old age, which suggests that $\mathrm{OA}$ is mediated by a combination of pro- and anti-inflammatory factors (da Costa et al. 2016). Spectral tracing experiments in mice have shown that the loss of chondrocytes proliferation activities due to aging may contribute to the progression of OA (Kozhemyakina et al. 2015). Accumulated DNA damage and oxidative stress also accelerate OA, and Didier et al. found that miR-24 inhibition of $\mathrm{p} 16^{\mathrm{INK} 4 \mathrm{~A}}$ expression prevented chondrocyte senescence (Philipot et al. 2014). In addition, OAassociated reductions in AMPK activity have been observed in aged mice, and this reduced activity indicated a significant reduction in mitochondrial biogenesis (Wang et al. 2015; Caramés et al. 2015) demonstrated a significant decrease in autophagy protein expression due to decreased AMPK activity, resulting in increased levels of apoptosis and cartilage deficit in OA mice (Caramés et al. 2015). In summary, interventions to remove senescent cells and slow down cellular senescence can be considered for treating musculoskeletal disorders such as sarcopenia and OA in the elderly.

\section{Anti-aging drugs}

Anti-aging is a very promising and yet challenging field, which is complicated by the mechanisms of aging. Some FDA approved drugs target one or more molecules to reduce cellular damage and prolong the healthspan. Next, this review will examine examples of the data obtained for these drugs in different model organisms and clinical trials to promote future directions for the continued study of aging biology. In addition, some of the possible side effects of these drugs in humans and animal models will be discussed.

\section{Metformin}

Metformin is a widely prescribed medication, which has been used to treat type 2 diabetes (T2D) in the past century (Pryor and Cabreiro 2015). At the same time, metformin has been shown to effectively reduce the pathogenesis and mortality of cardiovascular diseases (Palmer et al. 2016). Compared with other hypoglycemic drugs, elderly patients taking metformin have a lower risk of death due to cardiovascular disease (Schlender et al. 2017). In addition, recent studies have found that metformin has a positive effect on cancer, neurodegenerative diseases, and polycystic ovary syndrome (Barzilai et al. 2016). For example, metformin leads to decreased insulin levels and IGF-1 signaling (Liu et al. 2011), activation of AMPK (Cho et al. 2015), inhibition of mTOR (Nair et al. 2014; Pérez-Revuelta et al. 2014), a reduction in ROS (Batandier et al. 2006), and DNA damage (Shown in Fig. 1) (Algire et al. 2012; Cabreiro et al. 2013) found that metformin extended the lifespan of Caenorhabditis elegans by changing microbial folate and methionine metabolism (Cabreiro et al. 2013). Metformin also has positive prevention and treatment effects on agingrelated diseases. After continuous injection of metformin in SAMP8 mice for eight weeks, the expression of APPc99 and pTau in the mice brain was significantly reduced, and the learning and memory abilities of the mice were significantly improved (Farr et al. 2019). Ou et al. (2018) found that metformin exerted a neuroprotective effect on APP/PS1 mice via triggering 


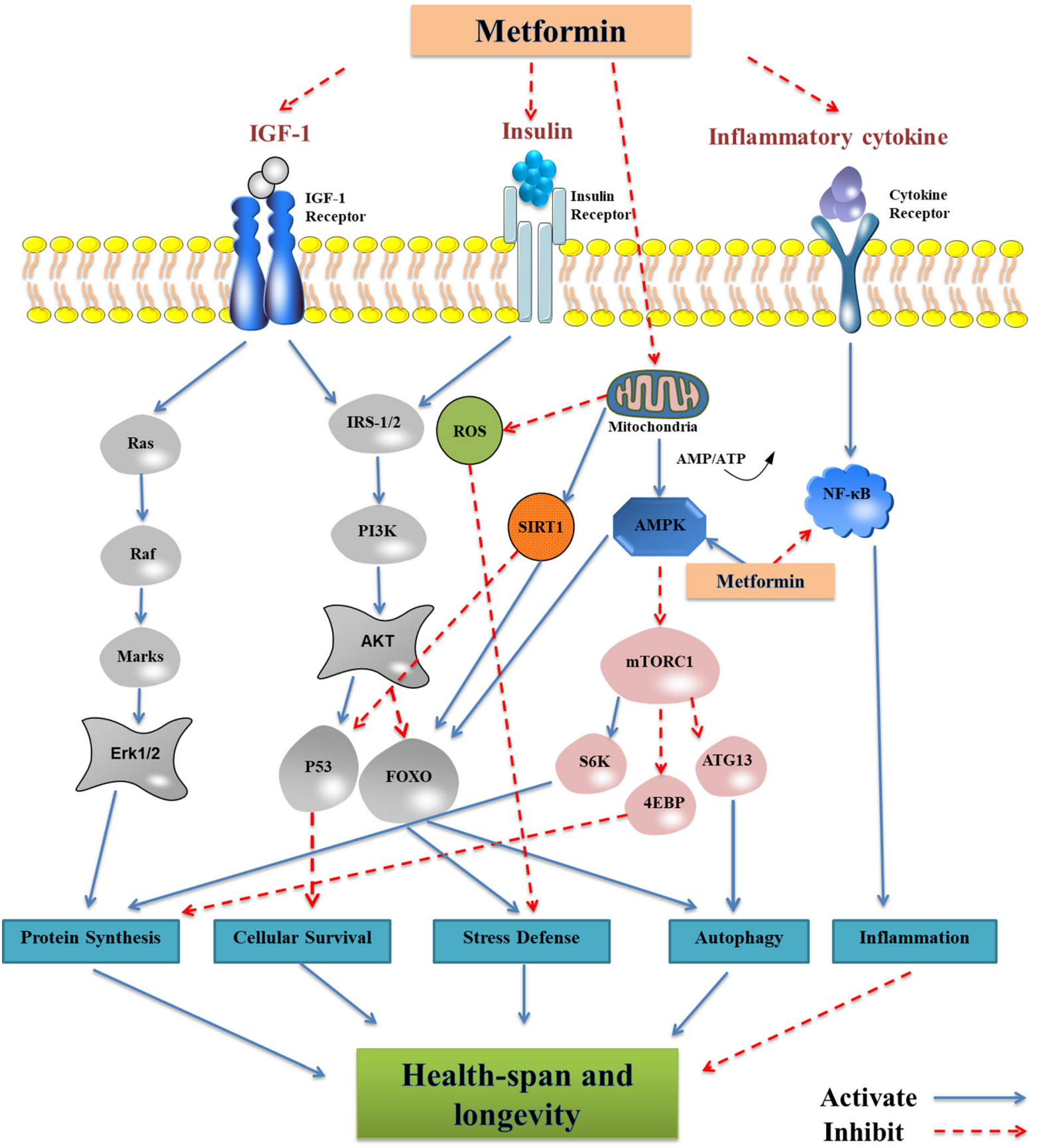

Fig. 1 Metformin targets the major pathways of aging. Extracellularly, metformin decreases insulin levels and IGF-1 signaling while influencing multiple cytokines to participate in anti-aging processes. Intracellularly, metformin reduces ROS production by inhibiting mitochondrial complex I in the electron transport chain generation and AMPK activation, simultaneous increase in mTOR signal inhibition and SIRT1 activation, which resulting in a longer life-span; Metformin affects inflammatory responses, cellular stress responses and autophagy responses, etc. by acting both inside and outside the cell. These cellular processes are the primary biological responses associated with aging 
neurogenesis and anti-inflammation by regulating AMPK/mTOR/S6K/Bace1 and AMPK/P65 NF- $\mathrm{BB}$ signaling in the hippocampus (Ou et al. 2018). In addition, metformin inhibited SNCA phosphorylation and aggregation, reduced oxidative stress, and improved MPTP-induced motor and cognitive dysfunction in mice with PD (Lu et al. 2016; Patil et al. 2014). A survey of older adults with diabetes in Singapore also found that long-term treatment with metformin in patients with T2D may reduce the risk of dementia and cognitive impairment ( $\mathrm{Ng}$ et al. 2014).

In addition to glucose homeostasis, the involvement of the tumor suppressor pathway is another target for metformin's action. A growing number of studies have shown that metformin has an inhibitory effect on some cancer cells in vivo and in vitro, such as rectal cancer and p53 mutant colon cancer (Algire et al. 2010; Buzzai et al. 2007; Gwinn et al. 2008; Hirsch et al. 2009; Hosono et al. 2010). In clinical trials, metformin also exerted excellent anti-cancer effects. A metaanalysis of diabetic patients treated with metformin and other drugs demonstrated a 30\% lower incidence of cancers in metformin-allocated patients, such as breast cancer, gastric cancer, and prostate cancer ( $\mathrm{Col}$ et al. 2012; Decensi et al. 2010; Tseng 2016). The survival rate was significantly improved for patients with pancreatic cancer who were treated with metformin (Li et al. 2017).

Although the therapeutic effect of metformin is well known for diabetes, there is evidence that longterm use of metformin may cause vitamin B12 deficiency in T2D patients and cause lactic acid accumulation in mice and humans (Aroda et al. 2016; Langan and Goodbred 2017; Marathe et al. 2017). In addition, the side effects of metformin also include irritation of the gastrointestinal tract, including diarrhea, nausea, flatulence, dyspepsia, vomiting, and abdominal discomfort, but in most cases, these symptoms are not obvious (McCreight et al. 2018). Stynen et al. (2018) reported that there are 745 proteins that are regulated by metformin treatment (Stynen et al. 2018). There is still uncertainty about whether these proteins demonstrate beneficial or potentially detrimental off-target effects when metformin is taken across the lifespan. Therefore, before providing metformin as a targeted aging drug, further research is needed to determine its broader effects, the molecular mechanism of action, and its safety implications.
Rapamycin

Rapamycin is a macrolide produced by Streptomyces hygroscopicus and was initially discovered as an antifungal agent. Recent studies have found that rapamycin can inhibit the mechanistic target of rapamycin (mTOR) protein kinase and extend the average lifespan of yeast, C. elegans, and fruit flies, but the role in mammals needs to be explored further (Johnson et al. 2013). Several other studies have shown that rapamycin could effectively extend the average and maximum lifespans of mice, such as C57BL/6, 129/SV, and UM-HET3 mice (Harrison et al. 2009; Anisimov et al. 2011; Chen et al. 2009; Neff et al. 2013). In addition, rapamycin has been found to inhibit tumorigenesis and extend the lifespan of many genetic early-onset models, such as p53 mutant mice, Apc mutant animals, Rb mutant mice, and HER-2/neu transgenic mice (Anisimov et al. 2010; Comas et al. 2012; Hasty et al. 2014). In addition, studies have found that rapamycin also has a neuroprotective effect. Oral rapamycin treatment could effectively improve cognitive function in elderly mice (Neff et al. 2013), reduce the pathological features of $\mathrm{AD}$, and maintain the integrity of the blood-brain barrier by preventing neuronal loss and improving cognitive function (Carosi and Sargeant 2019). In addition to exhibiting excellent anti-aging effects in animal models, rapamycin has also shown unexpected results in clinical trials. A recent metaanalysis showed that rapamycin has a positive effect on tuberous sclerosis - a rare multisystem disease with the formation of benign tumors and neurological disorders (Sasongko et al. 2016). A clinical trial conducted by Chung et al. showed that topical treatment with rapamycin significantly increased p $16^{\text {INKA4A }}$ and collagen IV protein levels and improved the histological appearance of the subjects' skin tissues, which suggests that rapamycin can be used to some extent as an anti-aging therapy in human beings (Chung et al. 2019). The mechanisms of the effects of rapamycin on lifespan are shown in Fig. 2.

As an FDA-approved drug, rapamycin has been used in humans as a post-transplant immunosuppressant and for the treatment of renal cell carcinoma, coronary artery stent coating, lymphovascular smooth muscle tumor, and autoimmune diseases (McCormack et al. 2011). However, various and serious negative effects limit its use. As a typical mTOR inhibitor, 


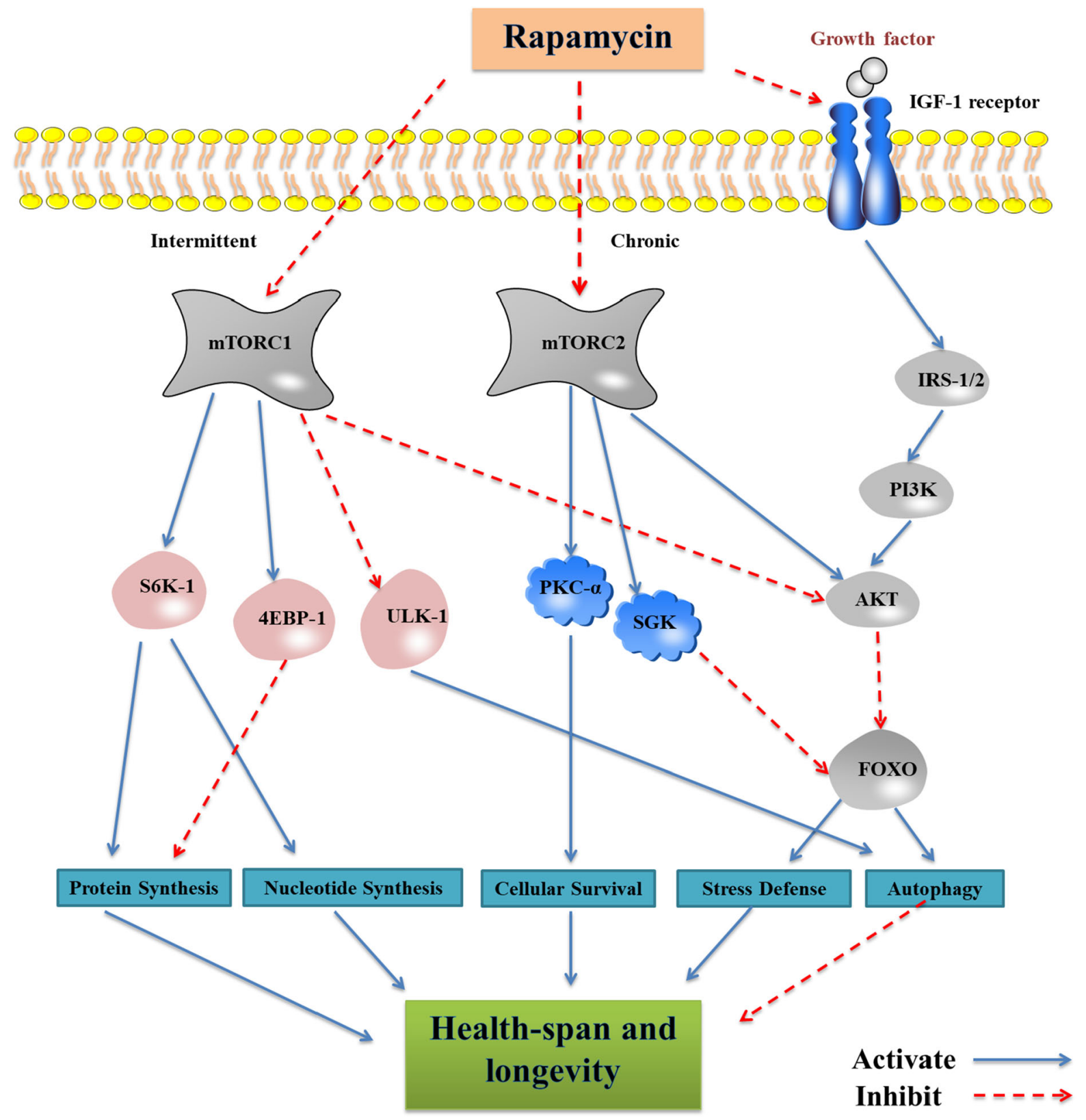

Fig. 2 Rapamycin regulates lifespan primarily through the mTOR signaling pathway. mTOR exists mainly in two functionally distinct complexes termed mTORC1 and mTORC2. Rapamycin inhibits mTORC1 on an intermittent basis, while long-term administration also inhibits mTORC2 in most tissues. Inhibition of mTORC1 promotes protein and

rapamycin acutely inhibits mTORC1, which could promote longevity partially through the inhibition of S6K1, protein translation, and increased autophagy. Conversely, a long-term overdose of rapamycin will nucleotide synthesis as well as autophagy responses, while also reducing cellular stress responses. These effects of rapamycin may promote longevity. In contrast, inhibition of mTORC2 leads to metabolic dysfunction and reduced lifespan, but the exact mechanism is unclear

inhibit the expression of mTORC2, which can result in metabolic dysfunction and a decrease in the lifespan of male mice through an as yet undetermined mechanism (Arriola Apelo and Lamming 2016). Therefore, 
further experiments are needed to determine the beneficial effects of rapamycin on mTORC1 inhibition-mediated aging and age-related diseases while minimizing the side effects associated with mTORC2.

\section{Resveratrol}

Resveratrol (3,5,4'-trihydroxystilbene) is a phytoalexin found in many plant species, such as grapes, peanuts, and berries, which could respond to mechanical injury, fungal infection, and UV radiation (Silva et al. 2019). Resveratrol mainly promotes health and lifespan in yeast and C. elegans by activating the sirtuin family (Cao et al. 2018; Howitz et al. 2003; Price et al. 2012; Wood et al. 2004). Resveratrol can promote the viability and proliferation of human umbilical cord mesenchymal stem cells (hUC-MSCs) in a dose-response manner, mitigating senescence and inducing the expression of SIRT1, while inhibiting the expression of p53 and p16 (Wang et al. 2016). Although resveratrol has not been reported to extend the lifespan of wild-type mammals, studies have shown that resveratrol supplementation can extend the lifespan of mammals with impaired metabolism. Resveratrol can reverse the physiological indicators of mice on a high-calorie diet to reduce the risk of death by about $31 \%$ (Baur et al. 2006; Gocmez et al. 2016) suggested that resveratrol was effective in preventing a cognitive deficit in $\mathrm{AD}$ rats by inhibiting the production of inflammatory cytokines (Gocmez et al. 2016). Resveratrol combined with hUC-MSCs transplantation could improve the learning and memory functions of $\mathrm{AD}$ mice and enhance neurogenesis (Wang et al. 2018). In addition, resveratrol can pass through the blood-brain barrier and act on the brain of elderly patients with $\mathrm{AD}$, prevent amyloid deposition, and reduce the formation of plaque (Sawda et al. 2017) Zhang et al. (2018) showed that resveratrol alleviated motor and cognitive deficits in PD model mice in a dose-dependent manner (Zhang et al. 2018). Emerging studies have shown that resveratrol can significantly reduce overall tumor development by promoting apoptosis, regulating the cell cycle, and inhibiting Cyclooxygenase (COX) activity and prostaglandin production (Kalra et al. 2008). Resveratrol has also been found to mediate the protective effects against inflammatory diseases and cardiovascular diseases through various mechanisms (Park et al. 2012; Tsai et al. 2014; Xia et al. 2017; Zhu et al. 2018). The mechanisms of the effects of resveratrol on lifespan are shown in Fig. 3.

Resveratrol has shown great promise in multiple animal models. However, its role in human clinical trials is still controversial. A 26-week intervention trial performed with 23 overweight elderly patients concluded that resveratrol supplementation might improve glucose metabolism, hippocampal functional connectivity, and memory function (Witte et al. 2014). But a recent meta-analysis showed the opposite result. A follow-up study on 225 patients showed that resveratrol did not have a positive effect on memory and cognition (Farzaei et al. 2018). In addition, Gliemann et al. (2013) showed that resveratrol supplementation reduced the positive effect of exercise training on blood pressure, blood cholesterol, and maximal oxygen uptake but did not affect the retardation of atherosclerosis (Gliemann et al. 2013). This phenomenon implies trying not to consume foods containing resveratrol during exercise. Resveratrol has been tolerated in animal experiments, but when administered in high doses, resveratrol may cause serious side effects such as diarrhea and local allergies (la Porte et al. 2010; Popat et al. 2013). In addition, resveratrol has a low bioavailability, which may limit its clinical application. A further challenge is that resveratrol is difficult to use in large-scale clinical trials at this stage.

\section{Senolytics}

Senolytics, drugs that selectively clear senescent cells, have been developed recently and may be a novel strategy for extending the healthspan and lifespan. Senescent cells increase several anti-apoptotic regulators, including dependence receptors, PI3K/Akt and BCL-2, which can jointly regulate the ability of cells to resist apoptosis (Zhu et al. 2015). Dasatinib (D) and quercetin $(\mathrm{Q})$ could induce apoptosis in senescent fat progenitor cells and alleviate several aging-related phenotypes in premature aging and natural aging mice induced by injury (Zhu et al. 2015). Navitoclax, a BCL-2 family inhibitor, could reduce the viability of senescent human umbilical vein epithelial cells (HUVEC) and IMR90, but it has no effects on human primary preadipocytes (Zhu et al. 2016). Other senolytics, such as ABT-737, A1331852 and A1155463 can also inhibit BCL-2 (Zhu et al. 2017) and clear senescent cells. Navitoclax could remove 


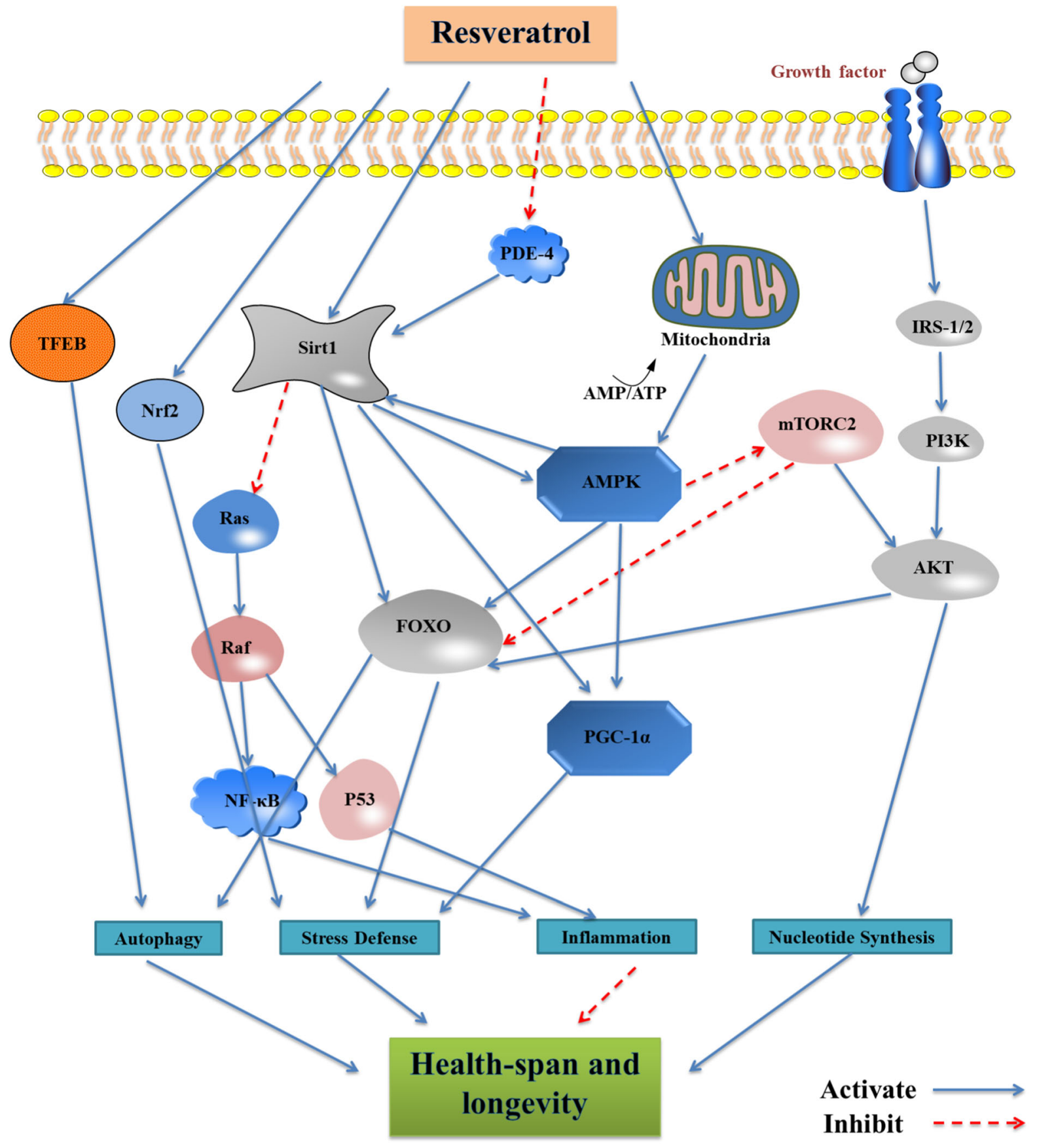

Fig. 3 Resveratrol is involved in anti-aging as an activator of the sirtuin family and the Nrf2 pathway. Inhibition of mitochondrial ATP production by resveratrol leads to activation of AMPK, which enhances NAD + availability thereby overcoming the rate limitation imposed by this cofactor on SIRT1 enzyme activity. In turn, resveratrol directly activates SIRT1 thereby positively controlling AMPK activity. Together, AMPK and SIRT1 form a positive feedback pathway to prolong life by modulating multiple downstream factors. In addition, resveratrol can act directly on transcriptional regulators thus acting as an anti-inflammatory and antioxidant effect 
SASP-targeted senescent cells (SNC) during the formation of atherosclerosis (Childs et al. 2016) and prevent hematopoietic SNC from rejuvenating (Chang et al. 2016). ATB263 clears a series of senescent cancer cells and eliminates chemotherapy-induced senescent cells, reducing cancer relapse and metastasis in mouse models (Demaria et al. 2017; Wang et al. 2017). Senolytic $(D+Q)$ treatment reduced the abundance of senescent cells in the brains of obese mice, restored neurogenesis, and reduced neuropsychiatric dysfunction (Musi et al. 2018; Ogrodnik et al. 2019; Zhang et al. 2019). In addition, senolytics may be effective for a variety of age-related diseases, such as idiopathic pulmonary fibrosis, sarcopenia, osteoarthritis, and glomerulosclerosis (Kim and Kim 2019). As research has progressed, senolytics have also shown promising results in clinical trials. Cox et al. (2015) conducted acute and chronic interventions using curcumin to treat elderly patients respectively and showed that both treatment regimens significantly improved their learning and memory abilities (Cox et al. 2015). Justice et al. (2019) found that senolytics $(\mathrm{D}+\mathrm{Q})$ significantly improved the clinical performance of 14 patients with idiopathic pulmonary fibrosis (IPF) (Justice et al. 2019). It can also effectively eliminate p16 INK4a-positive cells, reduce SA- $\beta$-gal activity, and decrease the release of inflammatory factors in diabetic nephropathy (Hickson et al. 2019; Rossman et al. 2018).

Although senolytic therapy exhibits exciting antiaging effects, the current understanding of senolytics has its own limitations. Navitoclax has been reported to cause severe thrombocytopenia and neutropenia, and these side effects limit its application (Niedernhofer and Robbins 2018). Another potential problem is tissue atrophy, which is caused by senescent cells being largely eliminated. In addition, senolytics eliminate not only the harmful effects of senescent cells but also their beneficial effects. Although cellular senescence is the cause of aging and aging-related diseases, senescent cells can also play a positive role. For example, senescence is an effective barrier against tumorigenesis in the early stages of cancer (Calcinotto et al. 2019). Therefore, the dual biological function of senolytics must be evaluated. Furthermore, it is necessary to advance the current version of senolytics by improving its targeting capability and selectively inhibiting its harmful effects on cells and tissues. Precise clinical trials of senolytics therapy have not yet been performed. More translational studies should also be considered.

\section{Caloric restriction}

Recently, progressively more research has recommended caloric restriction (CR) to reduce obesityinduced aging-related diseases (Salvestrini et al. 2019). The aim of $\mathrm{CR}$ is to reduce calorie intake without malnutrition and to improve the viability of organisms (Broskey et al. 2019). An accumulating number of studies have reported that $\mathrm{CR}$ has a positive effect on DNA repair and telomere mechanisms. The incidence of tumors in TERT transgenic (TgTERT) mice was significantly reduced with $\mathrm{CR}$, which also prolonged their lifespan compared to wild-type (WT) controls under the same diet (Vera et al. 2013). Reducing calorie intake can increase metabolic efficiency and prevent cell damage (Picca et al. 2017). It can also extend the lifespan of rodents and humans by reducing insulin, glucose, and the IGF-1 signaling pathway (Hwangbo et al. 2020; Pifferi and Aujard 2019a). In mammals, it is clear that CR induces the expression and activity of sirtuins in many tissues, which are closely related to aging (Imai and Guarente 2010). The positive effects of CR on inflammation and insulin resistance have been demonstrated in a rat model of age-associated inflammation by regulating

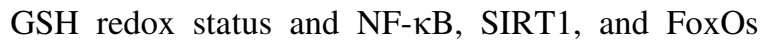
(Chung et al. 2011; Horrillo et al. 2011). Important improvements were shown in the onset and development of CVD and diabetes. The incidence of CVD is reduced with $\mathrm{CR}$ by controlling the mechanisms of maintaining cardiac activity, such as autophagy, proteasome-mediated turnover, apoptosis, and mitochondrial quality, to control its effects during aging (Rattan 2014). PGC-1 $\alpha$ expression and mitochondrial biogenesis stimulated by AMPK and SIRT1 in muscle have been associated with the reduction of insulin resistance, and the use of CR or CR mimickers, such as resveratrol or metformin, contribute to preventing the onset and the progression of the diseases (GerhartHines et al. 2007). Human clinical trials have also demonstrated positive effects of CR (Lorenzini 2014). A survey by Most et al. (2018) showed that continuous $\mathrm{CR}$ in healthy, nonobese individuals could reduce the incidence of cardiovascular disease by $30 \%$ (Most et al. 2018). Redman and Simin found that long-term $\mathrm{CR}$ without malnutrition could enhance the efficiency 

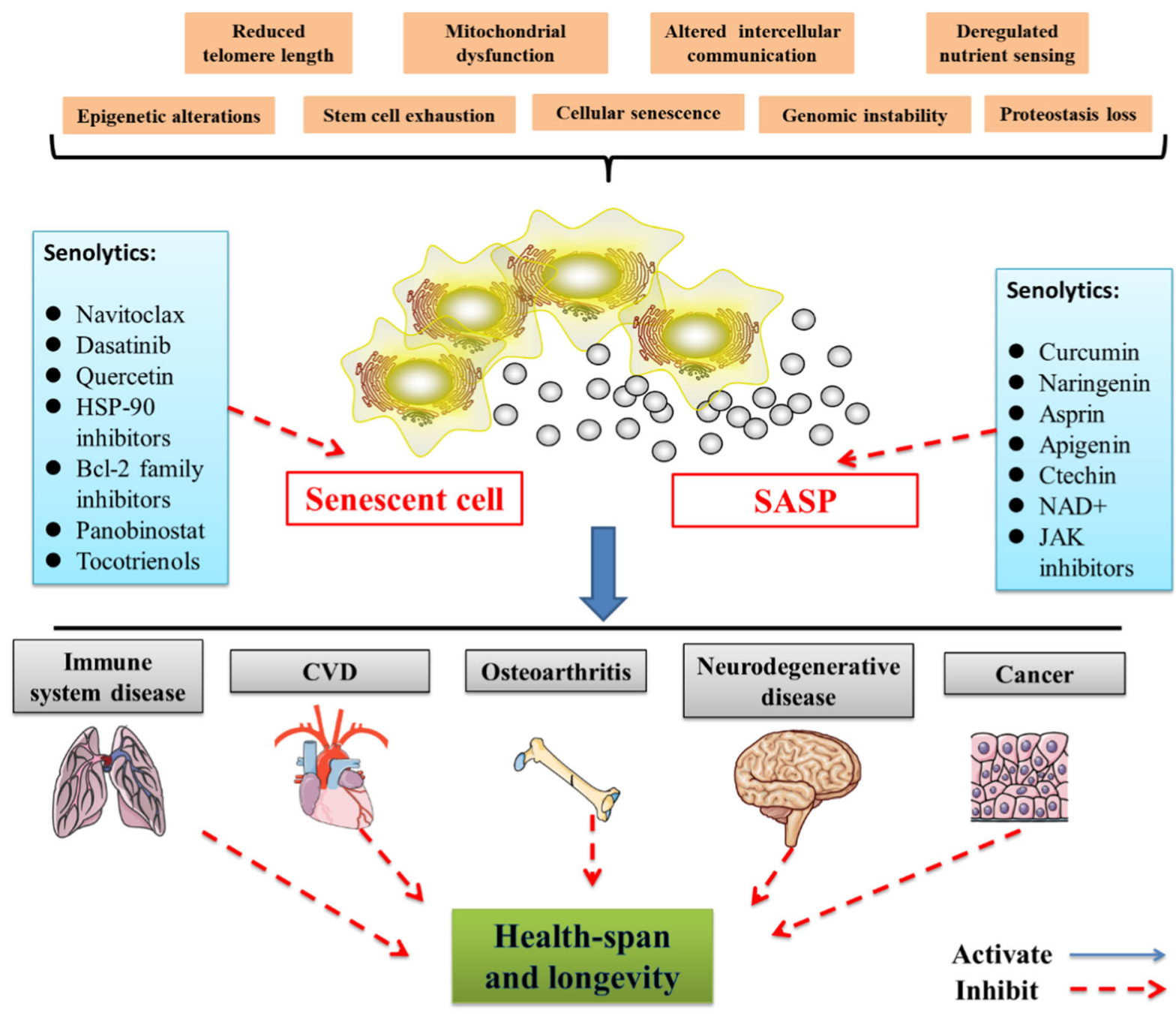

Fig. 4 Senolytic therapies target aging. During the aging process, senescent cells accumulate in large amounts in tissues and are associated with the development of various age-related diseases. Senolytics can help slow down the aging process by eliminating the accumulation of senescent cells, reducing agerelated diseases and prolonging healthspan. Uncontrolled

of resting energy expenditure, thereby reducing oxidative damage to tissues and organs (Redman et al. 2018), and inducing significant suppression of inflammation, as shown by a two-year CR dietary intervention (Meydani et al. 2016).

Despite the positive effects of moderate CR on human aging, some of the possible negative effects of CR should also be considered. As people get older, physiological reserves diminish, leading to reduced resistance to various stressors. In the case of malnutrition, these adverse factors can be magnified-a activation of SASP can cause chronic inflammation, leading to tissue dysfunction, this ultimately leads to aging and age-related diseases. Senolytics also can positively impact aging-related diseases by modulating the regulatory network of SASP in senescent cells and by inhibiting SASP from exerting its deleterious effects

problem that faces many older people. Therefore, CR should not be used as a potential intervention for treating diseases in this specific population (Pifferi and Aujard 2019b). Also, people with a low body mass index (BMI, less than $21 \mathrm{~kg} / \mathrm{m}^{2}$ ) should also be cautious of utilizing $\mathrm{CR}$, as this could lead to rapid weight loss and thus increase the risk of further health problems (Le Bourg and Redman 2018). In addition, a study by McGrath et al. found that exercise could cause bone loss and appeared to be harmful to the bones of mice in the $\mathrm{CR}$ group compared to the control 
group (McGrath et al. 2020). Clinical studies have also found that CR could decrease bone mineral density as well as increase the risk of osteoporotic fractures compared to a control group (Villareal et al. 2016). Therefore, before engaging in CR as a therapy to slow down the aging process, many factors, such as the patient's physical condition, mental state, and BMI, should be taken into consideration. Blindly engaging in dieting or CR should not be promoted (Fig. 4).

\section{Conclusions}

Medicine has undergone a gradual shift in its underlying concept, from "sick care" to "health care". That is to say, medicine is moving away from focusing on treatments after the occurrence of a disease towards intervening before the recognized risk factors progress to disease onset. Defining the hallmarks of aging helps to establish a framework of aging-related mechanisms and thus provides theoretical support for improving human health and extending the lifespan. Due to the continuously growing trend of an aging population, the anti-aging strategy is undoubtedly an increasingly important area for the pharmaceutical industry and public health organizations. However, considering the limitations and side effects of anti-aging drugs, there are presently too many concerns that need further clarification. Therefore, collaborative efforts from multidisciplinary researchers are required to advance these potential treatment strategies.

Funding This study was supported by National Natural Science Foundation of China (U2004201), Central Plains Thousand People Plan of Henan Province (204200510013), and Training plan for young excellent teachers in Colleges and Universities of Henan (2020GGJS008).

\section{Compliance with ethical standards}

Conflict of interest The authors declare no competing interests.

\section{References}

Acosta JC et al (2008) Chemokine signaling via the CXCR2 receptor\&nbsp;reinforces senescence. Cell 133:1006-1018. https://doi.org/10.1016/j.cell.2008.03.038

Acosta JC et al (2013) A complex secretory program orchestrated by the inflammasome controls paracrine senescence. Nat Cell Biol 15:978-990. https://doi.org/10.1038/ ncb2784

Algire C, Amrein L, Zakikhani M, Panasci L, Pollak M (2010) Metformin blocks the stimulative effect of a high-energy diet on colon carcinoma growth in vivo and is associated with reduced expression of fatty acid synthase . Endocr Relat Cancer 17:351-360. https://doi.org/10.1677/erc-090252

Algire C et al (2012) Metformin reduces endogenous reactive oxygen species and associated DNA damage. Cancer Prev Res 5:536-543. https://doi.org/10.1158/1940-6207.capr11-0536

Anisimov VN et al (2010) Rapamycin extends maximal lifespan in cancer-prone mice. Am J Pathol 176:2092-2097. https:// doi.org/10.2353/ajpath.2010.091050

Anisimov VN et al (2011) Rapamycin increases lifespan and inhibits spontaneous tumorigenesis in inbred female mice. Cell Cycle 10:4230-4236. https://doi.org/10.4161/cc.10. 24.18486

Apple DM, Solano-Fonseca R, Kokovay E (2017) Neurogenesis in the aging brain. Biochem Pharmacol 141:77-85. https:// doi.org/10.1016/j.bcp.2017.06.116

Aroda VR et al (2016) Long-term metformin use and vitamin B12 deficiency in the diabetes prevention program outcomes study. J Clin Endocrinol Metab 101:1754-1761. https://doi.org/10.1210/jc.2015-3754

Arriola Apelo SI, Lamming DW (2016) Rapamycin: an inhibiTOR of aging emerges from the soil of Easter Island. J Geront Ser A 71:841-849. https://doi.org/10.1093/ gerona/glw090

Baker DJ et al (2011) Clearance of p16Ink4a-positive senescent cells delays ageing-associated disorders. Nature 479:232-236. https://doi.org/10.1038/nature10600

Baker DJ et al (2016) Naturally occurring p16(Ink4a)-positive cells shorten healthy lifespan. Nature 530:184-189. https:// doi.org/10.1038/nature16932

Barzilai N, Crandall JP, Kritchevsky SB, Espeland MA (2016) Metformin as a tool to\&nbsp;target aging. Cell Metab 23:1060-1065. https://doi.org/10.1016/j.cmet.2016.05.011

Basisty N, Meyer JG, Schilling B (2018) Protein turnover in aging longevity. Proteomics 18:e1700108. https://doi.org/ 10.1002/pmic. 201700108

Batandier C, Guigas B, Detaille D, El-Mir MY, Fontaine E, Rigoulet M, Leverve XM (2006) The ROS production induced by a reverse-electron flux at respiratory-chain complex 1 is hampered by metformin. J Bioenerg Biomembr 38:33-42. https://doi.org/10.1007/s10863-0069003-8

Baur JA et al (2006) Resveratrol improves health and survival of mice on a high-calorie diet. Nature 444:337-342. https:// doi.org/10.1038/nature05354 
Baylin SB, Ohm JE (2006) Epigenetic gene silencing in cancer: a mechanism for early oncogenic pathway addiction? Nat Rev Cancer 6:107-116. https://doi.org/10.1038/nrc1799

Bitto A et al (2016) Transient rapamycin treatment can increase lifespan and healthspan in middle-aged mice. eLife. https:// doi.org/10.7554/eLife.16351

Broskey NT, Marlatt KL, Most J, Erickson ML, Irving BA, Redman LM (2019) The panacea of human aging: calorie restriction versus exercise. Exer Sport Sci Rev 47:169-175. https://doi.org/10.1249/jes.0000000000000193

Bullone M, Lavoie JP (2017) The contribution of oxidative stress and inflamm-aging in human and equine asthma. Int $\mathrm{J}$ Mol Sci. https://doi.org/10.3390/ijms18122612

Buzzai M et al (2007) Systemic treatment with the antidiabetic drug metformin selectively impairs p53-deficient\&nbsp;tumor cell growth. Cancer Res 67:6745-6752. https://doi.org/10.1158/0008-5472.can-06-4447

Cabreiro F et al (2013) Metformin retards aging in C. elegans by altering microbial folate\&nbsp; and methionine metabolism. Cell 153:228-239. https://doi.org/10.1016/j.cell. 2013.02.035

Calcinotto A, Kohli J, Zagato E, Pellegrini L, Demaria M, Alimonti A (2019) Cellular senescence: aging, cancer, and injury. Physiol Rev 99:1047-1078. https://doi.org/10. 1152/physrev.00020.2018

Cameron AR et al (2016) Anti-inflammatory effects of metformin irrespective of\&nbsp;diabetes status. Circ Res 119:652-665. https://doi.org/10.1161/circresaha.116. 308445

Campisi J, Kapahi P, Lithgow GJ, Melov S, Newman JC, Verdin E (2019) From discoveries in ageing research to therapeutics for healthy ageing. Nature 571:183-192. https:// doi.org/10.1038/s41586-019-1365-2

Cao L, Li W, Kim S, Brodie SG, Deng CX (2003) Senescence, aging, and malignant transformation mediated by p53 in mice lacking the Brcal full-length isoform. Genes Dev 17:201-213. https://doi.org/10.1101/gad.1050003

Cao W, Dou Y, Li A (2018) Resveratrol boosts cognitive function by targeting SIRT1. Neurochem Res 43:1705-1713. https://doi.org/10.1007/s11064-018-25868

Capell BC, Collins FS, Nabel EG (2007) Mechanisms of cardiovascular disease in accelerated aging syndromes. Circ Res 101:13-26. https://doi.org/10.1161/circresaha.107. 153692

Caramés B, Olmer M, Kiosses WB, Lotz MK (2015) The relationship of autophagy defects to cartilage damage during joint aging in a mouse model. Arthrit Rheumatol 67:1568-1576. https://doi.org/10.1002/art.39073

Carosi JM, Sargeant TJ (2019) Rapamycin and Alzheimer disease: a double-edged sword? Autophagy 15:1460-1462. https://doi.org/10.1080/15548627.2019.1615823

Chang J et al (2016) Clearance of senescent cells by ABT263 rejuvenates aged hematopoietic stem cells in mice. Nat Med 22:78-83. https://doi.org/10.1038/nm.4010

Chen C, Liu Y, Liu Y, Zheng P (2009) mTOR regulation and therapeutic rejuvenation of aging hematopoietic stem cells. Sci Signal 2:75. https://doi.org/10.1126/scisignal.2000559

Chen D, Kerr C (2019) The epigenetics of stem cell aging comes of age. Trends Cell Biol 29:563-568. https://doi.org/10. 1016/j.tcb.2019.03.006
Childs BG, Baker DJ, Wijshake T, Conover CA, Campisi J, van Deursen JM (2016) Senescent intimal foam cells are deleterious at all stages of atherosclerosis . Science 354:472-477. https://doi.org/10.1126/science.aaf6659

Cho K et al (2015) Antihyperglycemic mechanism of metformin occurs via the AMPK/LXR $\alpha / \mathrm{POMC}$ pathway. Sci Rep 5:8145. https://doi.org/10.1038/srep08145

Chung HY et al (2011) Molecular inflammation as an underlying mechanism of the aging process and age-related diseases. J Dent Res 90:830-840. https://doi.org/10.1177/ 0022034510387794

Chung CL et al (2019) Topical rapamycin reduces markers of senescence and aging in human skin: an exploratory, prospective, randomized trial. GeroScience 41:861-869. https://doi.org/10.1007/s11357-019-00113-y

Col NF, Ochs L, Springmann V, Aragaki AK, Chlebowski RT (2012) Metformin and breast cancer risk: a meta-analysis and critical literature review. Breast Cancer Res Treatm 135:639-646. https://doi.org/10.1007/s10549-012-2170-x

Comas M et al (2012) New nanoformulation of rapamycin Rapatar extends lifespan in homozygous p53-/- mice by\&nbsp;delaying carcinogenesis. Aging 4:715-722. https://doi.org/10.18632/aging.100496

Conboy IM, Rando TA (2012) Heterochronic parabiosis for the study of the effects of aging on stem cells and their niches. Cell Cycle 11:2260-2267. https://doi.org/10.4161/cc. 20437

Coppé JP, Desprez PY, Krtolica A, Campisi J (2010) The senescence-associated secretory phenotype: the dark side of tumor suppression. Ann Rev Pathol 5:99-118. https:// doi.org/10.1146/annurev-pathol-121808-102144

Cox KH, Pipingas A, Scholey AB (2015) Investigation of the effects of solid lipid curcumin on cognition and mood in a healthy older population. J Psychopharmacol 29:642-651. https://doi.org/10.1177/0269881114552744

da Costa JP, Vitorino R, Silva GM, Vogel C, Duarte AC, RochaSantos T (2016) A synopsis on aging-theories, mechanisms and future prospects. Ageing Res Rev 29:90-112. https:// doi.org/10.1016/j.arr.2016.06.005

Da Silva-Álvarez S, Guerra-Varela J, Sobrido-Cameán D, Quelle A, Barreiro-Iglesias A, Sánchez L, Collado M (2020) Cell senescence contributes to tissue regeneration\&nbsp;in zebrafish. Aging Cell 19:e13052. https://doi. org/10.1111/acel.13052

de Jesus BB, Vera E, Schneeberger K, Tejera AM, Ayuso E, Bosch F, Blasco MA (2012) Telomerase gene therapy in adult and old mice delays aging and increases longevity without increasing cancer. EMBO Mol Med 4:691-704. https://doi.org/10.1002/emmm.201200245

de Magalhães JP, Stevens M, Thornton D (2017) The business of anti-aging. Sci Trends Biotechnol 35:1062-1073. https:// doi.org/10.1016/j.tibtech.2017.07.004

Decensi A, Puntoni M, Goodwin P, Cazzaniga M, Gennari A, Bonanni B, Gandini S (2010) Metformin and cancer risk in diabetic patients: a systematic review and meta-analysis. Cancer Prevent Res 3:1451-1461. https://doi.org/10.1158/ 1940-6207.capr-10-0157

Demaria $\mathrm{M}$ et al (2017) Cellular senescence promotes adverse effects of chemotherapy and cancer relapse. Cancer Discov 7:165-176. https://doi.org/10.1158/2159-8290.cd-16-0241 
Di Daniele N et al (2017) Impact of Mediterranean diet on metabolic syndrome\&nbsp; cancer longevity. Oncotarget 8:8947-8979. https://doi.org/10.18632/oncotarget.13553

Diamanti-Kandarakis E et al (2017) Mechanisms in endocrinology: aging and anti-aging: a combo-endocrinology overview. Eur J Endocrinol 176:R283-Rr308. https://doi.org/10.1530/eje-16-1061

Diller ML, Kudchadkar RR, Delman KA, Lawson DH, Ford ML (2016) Balancing inflammation: the link between Th17 and regulatory T cells. Mediat Inflamm 2016:6309219. https:// doi.org/10.1155/2016/6309219

Doe $\mathrm{C}$ et al (2010) Expression of the $\mathrm{T}$ helper 17-associated cytokines IL-17A and IL-17F in asthma and COPD. Chest 138:1140-1147. https://doi.org/10.1378/chest.09-3058

Donato AJ, Machin DR, Lesniewski LA (2018) Mechanisms of dysfunction in the aging vasculature and role in age-related. Dis Circ Res 123:825-848. https://doi.org/10.1161/ circresaha.118.312563

Donev R, Kolev M, Millet B, Thome J (2009) Neuronal death in Alzheimer's disease and therapeutic opportunities. J Cell Mol Med 13:4329-4348. https://doi.org/10.1111/j.15824934.2009.00889.x

Fabricius K, Jacobsen JS, Pakkenberg B (2013) Effect of age on neocortical brain cells in $90+$ year old human females: a cell counting study. Neurobiol Aging 34:91-99. https://doi. org/10.1016/j.neurobiolaging.2012.06.009

Faget DV, Ren Q, Stewart SA (2019) Unmasking senescence: context-dependent effects of SASP in cancer. Nat Rev Cancer 19:439-453. https://doi.org/10.1038/s41568-0190156-2

Fan X, Wheatley EG, Villeda SA (2017) Mechanisms of hippocampal aging and the potential for rejuvenation. Annu Rev Neurosci 40:251-272. https://doi.org/10.1146/ annurev-neuro-072116-031357

Farr SA, Roesler E, Niehoff ML, Roby DA, McKee A, Morley JE (2019) Metformin improves learning and memory in the SAMP8 mouse model of Alzheimer's disease. J Alzheimer's Dis 68:1699-1710. https://doi.org/10.3233/ jad- 181240

Farzaei MH, Rahimi R, Nikfar S, Abdollahi M (2018) Effect of resveratrol on cognitive and memory performance and mood: a meta-analysis of 225 patients. Pharmacol Res 128:338-344. https://doi.org/10.1016/j.phrs.2017.08.009

Favalli EG (2020) Understanding the role of interleukin-6 (IL-6) in the joint and beyond: a comprehensive review of IL-6 inhibition for the management of rheumatoid. Arthritis Rheumatol Therapy 7:473-516. https://doi.org/10.1007/ s40744-020-00219-2

Foo MXR, Ong PF, Dreesen O (2019) Premature aging syndromes: from patients to mechanism. J Dermatol Sci 96:58-65. https://doi.org/10.1016/j.jdermsci.2019.10.003

Fraga MF et al (2005) Loss of acetylation at Lys16 and trimethylation at Lys20 of histone $\mathrm{H} 4$ is a common hallmark of human cancer. Nat Genet 37:391-400. https://doi. org/10.1038/ng 1531

Gaffney CJ, Pollard A, Barratt TF, Constantin-Teodosiu D, Greenhaff PL, Szewczyk NJ (2018) Greater loss of mitochondrial function with ageing is associated with earlier onset of sarcopenia in C. elegans. Aging 10:3382-3396. https://doi.org/10.18632/aging.101654
Gerhart-Hines Z et al (2007) Metabolic control of muscle mitochondrial function and fatty acid oxidation through SIRT1/PGC-1alpha. EMBO J 26:1913-1923. https://doi. org/10.1038/sj.emboj.7601633

Gillum MP et al (2011) SirT1 regulates adipose tissue inflammation. Diabetes 60:3235-3245. https://doi.org/10.2337/ db11-0616

Gliemann L et al (2013) Resveratrol blunts the positive effects of exercise training on cardiovascular health in aged men. J Physiol 591:5047-5059. https://doi.org/10.1113/jphysiol. 2013.258061

Gocmez SS, Gacar N, Utkan T, Gacar G, Scarpace PJ, Tumer N (2016) Protective effects of resveratrol on aging-induced cognitive impairment in rats. Neurobiol Learn Mem 131:131-136. https://doi.org/10.1016/j.nlm.2016.03.022

Goodell MA, Rando TA (2015) Stem cells and healthy aging. Science 350:1199-1204. https://doi.org/10.1126/science. aab3388

Gräff $\mathbf{J}$ et al (2012) An epigenetic blockade of cognitive functions in the neurodegenerating brain. Nature 483:222-226. https://doi.org/10.1038/nature10849

Green DR, Galluzzi L, Kroemer G (2011) Mitochondria and the autophagy-inflammation-cell death axis in organismal aging . Science 333:1109-1112. https://doi.org/10.1126/ science. 1201940

Grote C, Reinhardt D, Zhang M, Wang J (2019) Regulatory mechanisms and clinical manifestations of musculoskeletal aging. J Orthopaed Res 37:1475-1488. https://doi.org/ 10.1002 jor. 24292

Gustafson CE, Kim C, Weyand CM, Goronzy JJ (2020) Influence of immune aging on vaccine responses. J Allergy Clin Immunol 145:1309-1321. https://doi.org/10.1016/j.jaci. 2020.03.017

Gwinn DM et al (2008) AMPK phosphorylation of raptor mediates a metabolic checkpoint. Mol Cell 30:214-226. https://doi.org/10.1016/j.molcel.2008.03.003

Harman D (1965) The free radical theory of aging: effect of age on serum copper levels. J Gerontol 20:151-153. https://doi. org/10.1093/geronj/20.2.151

Harrison DE et al (2009) Rapamycin fed late in life extends lifespan in genetically heterogeneous mice. Nature 460:392-395. https://doi.org/10.1038/nature08221

Harry GJ (2013) Microglia during development and aging. Pharmacol Ther 139:313-326. https://doi.org/10.1016/j. pharmthera.2013.04.013

Hartley AV, Martin M, Lu T (2017) Aging: cancer-an unlikely couple. Aging 9:1949-1950. https://doi.org/10.18632/ aging.101295

Hasty P et al (2014) eRapa restores a normal life span in a FAP mouse model. Cancer Prevent Res 7:169-178. https://doi. org/10.1158/1940-6207.capr-13-0299

Hayflick L, Moorhead PS (1961) The serial cultivation of human diploid cell strains. Exp Cell Res 25:585-621. https://doi. org/10.1016/0014-4827(61)90192-6

Heidenreich PA et al (2011) Forecasting the future of cardiovascular disease in the United States: a policy statement from the American. Heart Assoc Circ 123:933-944. https:// doi.org/10.1161/CIR.0b013e31820a55f5

Hekimi S, Lapointe J, Wen Y (2011) Taking a "good" look at free radicals in the aging process. Trends Cell Biol 21:569-576. https://doi.org/10.1016/j.tcb.2011.06.008 
Hernandez-Segura A, de Jong TV, Melov S, Guryev V, Campisi J, Demaria M (2017) Unmasking transcriptional heterogeneity in senescent cells. Curr Biol 27:2652-2660.e2654. https://doi.org/10.1016/j.cub.2017.07.033

Hernandez-Segura A, Nehme J, Demaria M (2018) Hallmarks of cellular senescence. Trends Cell Biol 28:436-453. https:// doi.org/10.1016/j.tcb.2018.02.001

Herrmann M, Pusceddu I, März W, Herrmann W (2018) Telomere biology and age-related diseases. Clin Chem Lab Med 56:1210-1222. https://doi.org/10.1515/cclm-20170870

Hickson LJ et al (2019) Senolytics decrease senescent cells in humans: preliminary report from a clinical trial of Dasatinib plus Quercetin in individuals with diabetic kidney disease. EBioMedicine 47:446-456. https://doi.org/10. 1016/j.ebiom.2019.08.069

Hirsch HA, Iliopoulos D, Tsichlis PN, Struhl K (2009) Metformin selectively targets cancer stem cells, and acts together with chemotherapy to block tumor growth and prolong remission. Cancer Res 69:7507-7511. https://doi. org/10.1158/0008-5472.can-09-2994

Hood DA, Memme JM, Oliveira AN, Triolo M (2019) Maintenance of skeletal muscle mitochondria in health. Exer Aging Annu Rev Physiol 81:19-41. https://doi.org/10. 1146/annurev-physiol-020518-114310

Horrillo D et al (2011) Age-associated development of inflammation in Wistar rats: effects of caloric restriction. Arch Physiol Biochem 117:140-150. https://doi.org/10.3109/ 13813455.2011.577435

Hosono K et al (2010) Metformin suppresses azoxymethaneinduced colorectal aberrant crypt foci by activating AMPactivated protein kinase. Mol Carcinogen 49:662-671. https://doi.org/10.1002/mc.20637

Howitz KT et al (2003) Small molecule activators of sirtuins extend Saccharomyces\&nbsp;cerevisiae lifespan. Nature 425:191-196. https://doi.org/10.1038/nature01960

Hwangbo DS, Lee HY, Abozaid LS, Min KJ (2020) Mechanisms of lifespan regulation by calorie restriction and intermittent fasting in model organisms. Nutrients. https:// doi.org/10.3390/nu12041194

Imai S, Guarente L (2010) Ten years of NAD-dependent SIR2 family deacetylases: implications for metabolic diseases. Trends Pharmacological Sci 31:212-220. https://doi.org/ 10.1016/j.tips.2010.02.003

Janczura KJ et al (2018) Inhibition of HDAC3 reverses Alzheimer's disease-related pathologies in vitro and in the 3xTg-AD mouse model. Proc\&nbsp; Natl Acad Sci USA 115:E11148-E11157. https://doi.org/10.1073/pnas. 1805436115

Jankovic J, Kapadia AS (2001) Functional decline in Parkinson disease. Arch Neurol 58:1611-1615. https://doi.org/10. 1001/archneur.58.10.1611

Johnson SC, Rabinovitch PS, Kaeberlein M (2013) mTOR is a key modulator of ageing and age-related disease. Nature 493:338-345. https://doi.org/10.1038/nature11861

Justice JN et al (2019) Senolytics in idiopathic pulmonary fibrosis: results from a first-in-human, open-label pilot study. EBioMedicine 40:554-563. https://doi.org/10.1016/ j.ebiom.2018.12.052

Kalra N, Roy P, Prasad S, Shukla Y (2008) RETRACTED: Resveratrol induces apoptosis involving mitochondrial pathways in mouse skin tumorigenesis. Life Sci 82:348-358. https://doi.org/10.1016/j.lfs.2007.11.006

Kanaan NM, Kordower JH, Collier TJ (2007) Age-related accumulation of Marinesco bodies and lipofuscin in rhesus monkey midbrain dopamine neurons: relevance to selective neuronal vulnerability. J Comp Neurol 502:683-700. https://doi.org/10.1002/cne.21333

Kanaan NM, Kordower JH, Collier TJ (2008) Age and regionspecific responses of microglia, but not astrocytes, suggest a role in selective vulnerability of dopamine neurons after 1-methyl-4-phenyl-1,2,3,6-tetrahydropyridine exposure in monkeys. Glia 56:1199-1214. https://doi.org/10.1002/glia. 20690

Kane AE, Sinclair DA (2019) Epigenetic changes during aging and their reprogramming potential. Crit Rev Biochem Mol Biol 54:61-83. https://doi.org/10.1080/10409238.2019. 1570075

Kantarjian HM et al (2012) Multicenter, randomized, open-label, phase III trial of decitabine versus patient choice, with physician advice, of either supportive care or low-dose cytarabine for the treatment of older patients with newly diagnosed acute myeloid leukemia. J Clin Oncol 30:2670-2677. https://doi.org/10.1200/jco.2011.38.9429

Kapahi P, Kaeberlein M, Hansen M (2017) Dietary restriction and lifespan: lessons from invertebrate models. Ageing Res Rev 39:3-14. https://doi.org/10.1016/j.arr.2016.12.005

Kauppila TES, Kauppila JHK, Larsson NG (2017) Mammalian mitochondria and aging. An update. Cell Metab 25:57-71. https://doi.org/10.1016/j.cmet.2016.09.017

Kauppila TES et al (2018) Mutations of mitochondrial DNA are not major contributors to aging of fruit flies. Proc Natl Acad Sci USA 115:E9620-E9629. https://doi.org/10.1073/ pnas. 1721683115

Kaushik S, Cuervo AM (2015) Proteostasis and aging. Nat Med 21:1406-1415. https://doi.org/10.1038/nm.4001

Kawahara TL et al (2009) SIRT6 links histone H3 lysine 9 deacetylation to NF-kappaB-dependent gene expression and organismal life span. Cell 136:62-74. https://doi.org/ 10.1016/j.cell.2008.10.052

Keyes BE, Fuchs E (2018) Stem cells: aging and transcriptional fingerprints. J Cell Biol 217:79-92. https://doi.org/10. 1083/jcb.201708099

Kilgore M, Miller CA, Fass DM, Hennig KM, Haggarty SJ, Sweatt JD, Rumbaugh G (2010) Inhibitors of class 1 histone deacetylases reverse contextual memory deficits in a mouse model of Alzheimer's disease. Neuropsychopharmacology 35:870-880. https://doi.org/10.1038/npp.2009. 197

Kim EC, Kim JR (2019) Senotherapeutics: emerging strategy for healthy aging and age-related disease. BMB Rep 52:47-55. https://doi.org/10.5483/BMBRep.2019.52.1. 293

Klaips CL, Jayaraj GG, Hartl FU (2018) Pathways of cellular proteostasis in aging and disease. J Cell Biol 217:51-63. https://doi.org/10.1083/jcb.201709072

Kozhemyakina E et al (2015) Identification of a Prg4-expressing articular cartilage progenitor cell population in mice. Arthrit Rheumatol 67:1261-1273. https://doi.org/10.1002/ art. 39030

Kubben N, Misteli T (2017) Shared molecular and cellular mechanisms of premature ageing and ageing-associated 
diseases. Nat Rev Mol Cell Biol 18:595-609. https://doi. org/10.1038/nrm.2017.68

Kurz DJ et al (2006) Degenerative aortic valve stenosis, but not coronary disease, is associated with shorter telomere length in the elderly. Arterioscler Thromb Vasc Biol 26:e114-117. https://doi.org/10.1161/01.atv.0000222961.24912.69

la Porte C, Voduc N, Zhang G, Seguin I, Tardiff D, Singhal N, Cameron DW (2010) Steady-state pharmacokinetics and tolerability of trans-resveratrol $2000 \mathrm{mg}$ twice daily with food, quercetin and alcohol (ethanol) in healthy human subjects. Clin Pharmacokinet 49:449-454. https://doi.org/ 10.2165/11531820-000000000-00000

Lähteenvuo J, Rosenzweig A (2012) Effects of aging on angiogenesis. Circ Res 110:1252-1264. https://doi.org/10. 1161/circresaha.111.246116

Lakatta EG, Levy D (2003) Arterial and cardiac aging: major shareholders in cardiovascular disease enterprises: Part II: the aging heart in health: links to\&nbsp;heart disease. Circulation 107:346-354. https://doi.org/10.1161/01.cir. 0000048893.62841.f7

Langan RC, Goodbred AJ (2017) Vitamin B12 deficiency: recognition and management. Am Fam Phys 96:384-389

Lavasani M et al (2012) Muscle-derived stem/progenitor cell dysfunction limits healthspan and lifespan in a murine progeria model. Nat Commun 3:608. https://doi.org/10. 1038/ncomms 1611

Le Bourg E, Redman LM (2018) Do-it-yourself calorie restriction: the risks of simplistically translating findings in animal models to humans. BioEssays 40:e1800087. https:// doi.org/10.1002/bies.201800087

Leong I (2018) Sustained caloric restriction in health. Nat Rev Endocrinol 14:322. https://doi.org/10.1038/s41574-0180008-2

Li Y, Seto E (2016) HDACs and HDAC inhibitors in cancer development and therapy. Cold Spring Harbor Perspect Med. https://doi.org/10.1101/cshperspect.a026831

Li Y, Tollefsbol TO (2010) Impact on DNA methylation in cancer prevention and therapy by bioactive dietary components. Curr Med Chem 17:2141-2151. https://doi.org/ 10.2174/092986710791299966

Li X, Li T, Liu Z, Gou S, Wang C (2017) The effect of metformin on survival of patients with pancreatic cancer: a meta-analysis. Sci Rep 7:5825. https://doi.org/10.1038/ s41598-017-06207-x

Li YR, Li S, Lin CC (2018) Effect of resveratrol and pterostilbene on aging and longevity . BioFactors 44:69-82. https:// doi.org/10.1002/biof.1400

Liddelow SA, Barres BA (2017) Reactive astrocytes: production, function, and therapeutic potential. Immunity 46:957-967. https://doi.org/10.1016/j.immuni.2017.06.006

Lin CL et al (2019) HDAC1 and HDAC2 double knockout triggers cell apoptosis in advanced thyroid cancer. Int J Mol Sci. https://doi.org/10.3390/ijms20020454

Liu B, Fan Z, Edgerton SM, Yang X, Lind SE, Thor AD (2011) Potent anti-proliferative effects of metformin on trastuzumab-resistant breast cancer cells via inhibition of erbB2/ IGF-1 receptor interactions. Cell Cycle 10:2959-2966. https://doi.org/10.4161/cc.10.17.16359

López-Otín C, Blasco MA, Partridge L, Serrano M, Kroemer G (2013) The hallmarks of aging. Cell 153:1194-1217. https://doi.org/10.1016/j.cell.2013.05.039
Lorenzini A (2014) How much should we weigh for a long and healthy life span? The need to reconcile caloric restriction versus longevity with body mass index versus mortality data . Front Endocrinol 5:121. https://doi.org/10.3389/ fendo.2014.00121

Lu M, Su C, Qiao C, Bian Y, Ding J, Hu G (2016) Metformin prevents dopaminergic neuron death in MPTP/P-induced mouse model of Parkinson's disease via autophagy and mitochondrial ROS clearance. Int J Neuropsychopharmacol. https://doi.org/10.1093/ijnp/pyw047

Lublóy Á (2020) Medical crowdfunding in a healthcare system with universal coverage: an exploratory study. BMC Public Health 20:1672. https://doi.org/10.1186/s12889-020-09693-3

Ma S et al (2019) Histone deacetylases inhibitor MS-275 suppresses human esophageal squamous cell carcinoma cell growth and progression via the PI3K/Akt/mTOR pathway. J Cell Physiol 234:22400-22410. https://doi.org/10.1002/ jcp. 28805

Maierhofer A et al (2019) Epigenetic signatures of Werner syndrome occur early in life and are distinct from normal epigenetic aging processes. Aging Cell 18:e12995. https:// doi.org/10.1111/acel.12995

Marathe PH, Gao HX, Close KL (2017) American Diabetes Association Standards of Medical Care in Diabetes 2017. J Diabet 9:320-324. https://doi.org/10.1111/1753-0407. 12524

Matheu A et al (2007) Delayed ageing through damage protection by the Arf/p53 pathway. Nature 448:375-379. https://doi.org/10.1038/nature05949

Mathew R, Pal Bhadra M, Bhadra U (2017) Insulin/insulin-like growth factor-1 signalling (IIS) based regulation of lifespan across species. Biogerontology 18:35-53. https://doi. org/10.1007/s10522-016-9670-8

McCormack FX et al (2011) Efficacy and safety of sirolimus in lymphangioleiomyomatosis. $\mathrm{N}$ Engl J Med 364:1595-1606. https://doi.org/10.1056/NEJMoa1100391

McCreight LJ et al (2018) Pharmacokinetics of metformin in patients with gastrointestinal intolerance. Diabet Obes Metab 20:1593-1601. https://doi.org/10.1111/dom.13264

McGrath C et al (2020) Exercise degrades bone in caloric restriction, despite suppression of marrow adipose tissue (MAT). J Bone Miner Res 35:106-115. https://doi.org/10. 1002/jbmr.3872

Mensà E, Latini S, Ramini D, Storci G, Bonafè M, Olivieri F (2019) The telomere world and aging: analytical challenges and future perspectives. Ageing Res Rev 50:27-42. https://doi.org/10.1016/j.arr.2019.01.004

Meydani SN et al (2016) Long-term moderate calorie restriction inhibits inflammation without impairing cell-mediated immunity: a randomized controlled trial in non-obese humans. Aging 8:1416-1431. https://doi.org/10.18632/ aging.100994

Moiseeva O et al (2013) Metformin inhibits the senescenceassociated secretory phenotype by interfering with IKK/ NF- $\kappa B$ activation. Aging Cell 12:489-498. https://doi.org/ 10.1111/acel.12075

Morigi M, Perico L, Benigni A (2018) Sirtuins in renal health and disease. J Am Soc Nephrol 29:1799-1809. https://doi. org/10.1681/asn.2017111218

Most J, Gilmore LA, Smith SR, Han H, Ravussin E, Redman LM (2018) Significant improvement in cardiometabolic 
health in healthy nonobese individuals during caloric restriction-induced weight loss and weight loss maintenance. Am J Physiol Endocrinology Metab 314:E396E405. https://doi.org/10.1152/ajpendo.00261.2017

Musci RV et al (2020) The Dunkin Hartley Guinea pig is a model of primary osteoarthritis that also exhibits early onset myofiber remodeling that resembles human musculoskeletal aging. Front Physiol 11:571372. https://doi.org/ 10.3389/fphys.2020.571372

Musi N, Valentine JM, Sickora KR, Baeuerle E, Thompson CS, Shen Q, Orr ME (2018) Tau protein aggregation is associated with cellular senescence in the brain. Aging Cell 17:e12840. https://doi.org/10.1111/acel.12840

Nair V, Sreevalsan S, Basha R, Abdelrahim M, Abudayyeh A, Rodrigues Hoffman A, Safe S (2014) Mechanism of metformin-dependent inhibition of mammalian target of rapamycin (mTOR) and Ras activity in pancreatic cancer: role of specificity protein (Sp) transcription factors. J Biol Chem 289:27692-27701. https://doi.org/10.1074/jbc. M114.592576

Neff F et al (2013) Rapamycin extends murine lifespan but has limited effects on aging. J Clin Investig 123:3272-3291. https://doi.org/10.1172/jci67674

Nelson G, Kucheryavenko O, Wordsworth J, von Zglinicki T (2018) The senescent bystander effect is caused by ROSactivated NF- $\kappa B$ signalling. Mech Ageing Dev 170:30-36. https://doi.org/10.1016/j.mad.2017.08.005

Ng TP, Feng L, Yap KB, Lee TS, Tan CH, Winblad B (2014) Long-term metformin usage and cognitive function among older adults with diabetes. J Alzheimer's Dis 41:61-68. https://doi.org/10.3233/jad-131901

Niedernhofer LJ, Robbins PD (2018) Senotherapeutics for healthy ageing. Nat Rev Drug Discov 17:377. https://doi. org/10.1038/nrd.2018.44

Njie EG, Boelen E, Stassen FR, Steinbusch HW, Borchelt DR, Streit WJ (2012) Ex vivo cultures of microglia from young and aged rodent brain reveal age-related changes in microglial function. Neurobiol Aging 33:195.e191-112. https://doi.org/10.1016/j.neurobiolaging.2010.05.008

Ogrodnik M et al (2019) Obesity-induced cellular senescence drives anxiety and impairs. Neurogen Cell Metab 29:1233. https://doi.org/10.1016/j.cmet.2019.01.013

Olah $\mathrm{M}$ et al (2018) A transcriptomic atlas of aged human microglia. Nat Commun 9:539. https://doi.org/10.1038/ s41467-018-02926-5

Osorio FG et al (2012) Nuclear lamina defects cause ATMdependent NF- $\kappa \mathrm{B}$ activation and link accelerated aging to a systemic inflammatory response. Genes Dev 26:2311-2324. https://doi.org/10.1101/gad.197954.112

Ou Z et al (2018) Metformin treatment prevents amyloid plaque deposition and memory impairment in APP/PS1 mice. Brain Behav Immun 69:351-363. https://doi.org/10.1016/ j.bbi.2017.12.009

Palmer SC et al (2016) Comparison of clinical outcomes and adverse events associated with glucose-lowering drugs in patients with type 2 diabetes: a meta-analysis. Jama 316:313-324. https://doi.org/10.1001/jama.2016.9400

Paneni F, Diaz Cañestro C, Libby P, Lüscher TF, Camici GG (2017) The aging cardiovascular system: understanding it at the cellular and clinical levels. J Am Coll Cardiol 69:1952-1967. https://doi.org/10.1016/j.jacc.2017.01.064
Park DW, Kim JS, Chin BR, Baek SH (2012) Resveratrol inhibits inflammation induced by heat-killed Listeria monocytogenes. J Med Food 15:788-794. https://doi.org/ 10.1089/jmf.2012.2194

Patil SP, Jain PD, Ghumatkar PJ, Tambe R, Sathaye S (2014) Neuroprotective effect of metformin in MPTP-induced Parkinson's disease in mice. Neuroscience 277:747-754. https://doi.org/10.1016/j.neuroscience.2014.07.046

Patrick M, Weng NP (2019) Expression and regulation of telomerase in human $\mathrm{T}$ cell differentiation, activation, aging and diseases. Cell Immunol 345:103989. https://doi. org/10.1016/j.cellimm.2019.103989

Pereira B, Xu XN, Akbar AN (2020) Targeting inflammation and immunosenescence to improve vaccine responses in the elderly. Front Immunol 11:583019. https://doi.org/10. 3389/fimmu.2020.583019

Pérez-Revuelta BI, Hettich MM, Ciociaro A, Rotermund C, Kahle PJ, Krauss S, Di Monte DA (2014) Metformin lowers Ser-129 phosphorylated $\alpha$-synuclein levels via mTOR-dependent protein phosphatase $2 \mathrm{~A}$ activation. Cell Death Dis 5:e1209. https://doi.org/10.1038/cddis.2014.175

Philipot D et al (2014) p16INK4a and its regulator miR-24 link senescence and chondrocyte terminal differentiation-associated matrix remodeling in osteoarthritis. Arthritis Res Therapy 16:R58. https://doi.org/10.1186/ar4494

Picca A, Pesce V, Lezza AMS (2017) Does eating less make you live longer and better? An update on calorie restriction. Clin Interv Aging 12:1887-1902. https://doi.org/10.2147/ cia.s 126458

Pietrobon AJ, Teixeira FME, Sato MN (2020) Immunosenescence and inflammaging: risk factors of severe COVID-19 in older people. Front Immunol 11:579220. https://doi.org/ 10.3389/fimmu.2020.579220

Pifferi F, Aujard F (2019) Caloric restriction, longevity and aging: recent contributions from human and non-human primate studies. Prog Neuro-Psychopharmacol Biol Psychiatry 95:109702. https://doi.org/10.1016/j.pnpbp.2019. 109702

Pifferi F, Aujard F (2019) Caloric restriction, longevity and aging: Recent contributions from human and non-human primate studies. Prog Neuro-Psychopharmacol Biol Psychiatry 95:109702. https://doi.org/10.1016/j.pnpbp.2019. 109702

Popat R et al (2013) A phase 2 study of SRT501 (resveratrol) with bortezomib for patients with relapsed and or refractory multiple myeloma. Br J Haematol 160:714-717. https://doi.org/10.1111/bjh.12154

Price NL et al (2012) SIRT1 is required for AMPK activation and the beneficial effects of resveratrol on mitochondrial function. Cell Metabol 15:675-690. https://doi.org/10. 1016/j.cmet.2012.04.003

Pringsheim T, Jette N, Frolkis A, Steeves TD (2014) The prevalence of Parkinson's disease: a systematic review and meta-analysis. J Movement Disord Soc 29:1583-1590. https://doi.org/10.1002/mds.25945

Pryor R, Cabreiro F (2015) Repurposing metformin: an old drug with new tricks in its binding pockets. Biochem $\mathrm{J}$ 471:307-322. https://doi.org/10.1042/bj20150497

Raphael I, Joern RR, Forsthuber TG (2020) Memory CD4(+) T cells in immunity and autoimmune diseases. Cells 7:8. https://doi.org/10.3390/cells9030531 
Rattan SI (2014) Aging is not a disease: implications for intervention. Aging Dis 5:196-202. https://doi.org/10.14336/ ad.2014.0500196

Ravi V et al (2019) SIRT6 transcriptionally regulates global protein synthesis through transcription factor Sp1 independent of its deacetylase activity. Nucleic Acids Res 47:9115-9131. https://doi.org/10.1093/nar/gkz648

Ray D, Yung R (2018) Immune senescence, epigenetics and autoimmunity. Clin Immunol 196:59-63. https://doi.org/ 10.1016/j.clim.2018.04.002

Redman LM, Smith SR, Burton JH, Martin CK, Il'yasova D, Ravussin E (2018) Metabolic slowing and reduced oxidative damage with sustained caloric restriction support the rate of living and oxidative damage theories of aging. Aging Cell Metab 27:805-815.e804. https://doi.org/10. 1016/j.cmet.2018.02.019

Ritschka B et al (2017) The senescence-associated secretory phenotype induces cellular plasticity and tissue regeneration. Genes Dev 31:172-183. https://doi.org/10.1101/gad. 290635.116

Rossman MJ et al (2018) Chronic supplementation with a mitochondrial antioxidant (mitoq) improves vascular function in healthy older adults. Hypertension 71:1056-1063. https://doi. org/10.1161/hypertensionaha.117.10787

Rufer N et al (1999) Telomere fluorescence measurements in granulocytes and $\mathrm{T}$ lymphocyte subsets point to a high turnover of hematopoietic stem cells and memory $\mathrm{T}$ cells in early childhood. J Exp Med 190:157-167. https://doi.org/ 10.1084/jem.190.2.157

Sadighi Akha AA (2018) Aging and the immune system: an overview. J Immunol Methods 463:21-26. https://doi.org/ 10.1016/j.jim.2018.08.005

Salminen A, Kaarniranta K, Kauppinen A (2012) Inflammaging: disturbed interplay between autophagy and\&nbsp;inflammasomes. Aging 4:166-175. https://doi.org/10.18632/ aging. 100444

Salminen A, Kauppinen A, Kaarniranta K (2017) FGF21 activates AMPK signaling: impact on metabolic regulation and the aging process. J Mol Med 95:123-131. https://doi.org/ 10.1007/s00109-016-1477-1

Salvestrini V, Sell C, Lorenzini A (2019) Obesity may accelerate the aging process . Front Endocrinol 10:266. https:// doi.org/10.3389/fendo.2019.00266

Santos J, Leitão-Correia F, Sousa MJ, Leão C (2016) Dietary restriction and nutrient balance in aging. Oxid Med Cell Longev 2016:4010357. https://doi.org/10.1155/2016/ 4010357

Saretzki G (2018) Telomeres, telomerase and ageing. Sub-cell Biochem 90:221-308. https://doi.org/10.1007/978-98113-2835-0_9

Sasongko TH, Ismail NF, Zabidi-Hussin Z (2016) Rapamycin and rapalogs for tuberous sclerosis complex. Cochrane Database Syst Rev 7:011272. https://doi.org/10.1002/ 14651858.CD011272.pub2

Sawda C, Moussa C, Turner RS (2017) Resveratrol for Alzheimer's disease. Ann N Y Acad Sci 1403:142-149. https://doi.org/10.1111/nyas.13431

Schlender L et al (2017) Efficacy and safety of metformin in the management of type 2 diabetes mellitus in older adults: a systematic review for the development of recommendations to reduce potentially inappropriate prescribing. BMC
Geriatr 17:227. https://doi.org/10.1186/s12877-017-05745

Senovilla L et al (2012) An immunosurveillance mechanism controls cancer cell ploidy. Science 337:1678-1684. https://doi.org/10.1126/science. 1224922

Shay JW (2016) Role of telomeres and telomerase in aging and cancer. Cancer Discov 6:584-593. https://doi.org/10.1158/ 2159-8290.cd-16-0062

Sheth KA et al (2018) Muscle strength and size are associated with motor unit connectivity in aged mice. Neurobiol Aging 67:128-136. https://doi.org/10.1016/j. neurobiolaging.2018.03.016

Silva P, Sureda A, Tur JA, Andreoletti P, Cherkaoui-Malki M, Latruffe N (2019) How efficient is resveratrol as an antioxidant of the Mediterranean diet, towards alterations during the aging process? Free Radic Res 53:1101-1112. https://doi.org/10.1080/10715762.2019.1614176

Smith BD, Smith GL, Hurria A, Hortobagyi GN, Buchholz TA (2009) Future of cancer incidence in the United States: burdens upon an aging\&nbsp;changing nation. J Clin Oncol 27:2758-2765. https://doi.org/10.1200/jco.2008.20. 8983

Sorrentino V et al (2017) Enhancing mitochondrial proteostasis reduces amyloid- $\beta$ proteotoxicity. Nature 552:187-193. https://doi.org/10.1038/nature25143

Spescha RD et al (2013) Deletion of the ageing gene p66(Shc) reduces early stroke size following ischaemia/reperfusion brain injury. Eur Heart J 34:96-103. https://doi.org/10. 1093/eurheartj/ehs331

Spescha RD et al (2015) Post-ischaemic silencing of p66Shc reduces ischaemia/reperfusion brain injury and its expression correlates to clinical outcome in stroke. Eur Heart $\mathrm{J}$ 36:1590-1600. https://doi.org/10.1093/eurheartj/ehv140

Stynen B et al (2018) Changes of cell biochemical states are revealed in protein homomeric. Complex Dyn Cell 175:1418-1429.e1419. https://doi.org/10.1016/j.cell.2018. 09.050

Tiwari V, Wilson DM (2019) DNA damage and associated DNA repair defects in disease and premature. Aging Am J Hum Genet 105:237-257. https://doi.org/10.1016/j.ajhg. 2019.06.005

Tizazu AM et al (2019) Metformin monotherapy downregulates diabetes-associated inflammatory status and impacts on mortality. Front Physiol 10:572. https://doi.org/10.3389/ fphys.2019.00572

Trevisan K, Cristina-Pereira R, Silva-Amaral D, Aversi-Ferreira TA (2019) Theories of aging and the prevalence of Alzheimer's disease. BioMed Res Int 2019:9171424. https:// doi.org/10.1155/2019/9171424

Tsai CF, Wang KT, Chen LG, Lee CJ, Tseng SH, Wang CC (2014) Anti-inflammatory effects of Vitis thunbergii var. taiwaniana on knee damage associated with arthritis. J Med Food 17:479-486. https://doi.org/10.1089/jmf.2013.2914

Tseng CH (2016) Metformin reduces gastric cancer risk in patients with type $2 \& n b s p$;iabetes mellitus. Aging 8:1636-1649. https://doi.org/10.18632/aging.101019

Ullah M, Sun Z (2019) Klotho deficiency accelerates stem cells aging by impairing telomerase activity. J Gerontol Ser A 74:1396-1407. https://doi.org/10.1093/gerona/gly261

van Deursen JM (2014) The role of senescent cells in ageing. Nature 509:439-446. https://doi.org/10.1038/nature13193 
Vera E, Bernardes de Jesus B, Foronda M, Flores JM, Blasco MA (2013) Telomerase reverse transcriptase synergizes with calorie restriction to increase health span and extend mouse longevity. PLoS ONE 8:e53760. https://doi.org/10. 1371/journal.pone.0053760

Villareal DT et al (2016) Effect of two-year caloric restriction on bone metabolism and bone mineral density in non-obese younger adults: a randomized clinical trial. J Bone Miner Res 31:40-51. https://doi.org/10.1002/jbmr.2701

Wang Y, Zhao X, Lotz M, Terkeltaub R, Liu-Bryan R (2015) Mitochondrial biogenesis is impaired in osteoarthritis chondrocytes but reversible via peroxisome proliferatoractivated receptor $\gamma$ coactivator $1 \alpha \& n b s p$; Arthrit Rheumatol 67:2141-2153. https://doi.org/10.1002/art. 39182

Wang X et al (2016) Resveratrol exerts dosage-dependent effects on the self-renewal and neural differentiation of hUC-MSCs. Mol Cells 39:418-425. https://doi.org/10. 14348/molcells.2016.2345

Wang L et al (2017) High-throughput functional genetic and compound screens identify targets for senescence induction in cancer. Cell Rep 21:773-783. https://doi.org/10. 1016/j.celrep.2017.09.085

Wang X et al (2018) Resveratrol promotes hUC-MSCs engraftment and neural repair in a mouse model of Alzheimer's disease. Behav Brain Res 339:297-304. https:// doi.org/10.1016/j.bbr.2017.10.032

Wiley CD et al (2016) Mitochondrial dysfunction induces senescence with a distinct secretory. Phenotype Cell Metab 23:303-314. https://doi.org/10.1016/j.cmet.2015.11.011

Winnik S, Auwerx J, Sinclair DA, Matter CM (2015) Protective effects of sirtuins in cardiovascular diseases: from bench to bedside. Eur Heart J 36:3404-3412. https://doi.org/10. 1093/eurheartj/ehv290

Witte AV, Kerti L, Margulies DS, Flöel A (2014) Effects of resveratrol on memory performance, hippocampal functional connectivity, and glucose metabolism in healthy older adults. J Neurosci 34:7862-7870. https://doi.org/10. 1523/jneurosci.0385-14.2014

Wong SQ, Kumar AV, Mills J, Lapierre LR (2020) Autophagy in aging and longevity. Hum Genet 139:277-290. https:// doi.org/10.1007/s00439-019-02031-7

Wood JG, Rogina B, Lavu S, Howitz K, Helfand SL, Tatar M, Sinclair D (2004) Sirtuin activators mimic caloric restriction and delay ageing\&nbsp;in metazoans. Nature 430:686-689. https://doi.org/10.1038/nature02789

Wyss-Coray T, Rogers J (2012) Inflammation in Alzheimer disease: a brief review of the basic science and clinical literature. Cold Spring Harbor Perspect Med 2:a006346. https://doi.org/10.1101/cshperspect.a006346

Xia N, Förstermann U, Li H (2017) Effects of resveratrol on eNOS in the endothelium and the perivascular adipose tissue . Ann N Y Acad Sci 1403:132-141. https://doi.org/ 10.1111/nyas. 13397

Xia X, Jiang Q, McDermott J, Han JJ (2018) Aging and Alzheimer's disease: comparison and associations from molecular to system level. Aging Cell 17:e12802. https:// doi.org/10.1111/acel.12802
Xiong C, Zhang Z, Baht GS, Terrando N (2018) A mouse model of orthopedic surgery to study postoperative cognitive dysfunction and tissue regeneration. J Visualiz Exp. https:// doi.org/10.3791/56701

$\mathrm{Xu}$ S et al (2016) SIRT6 protects against endothelial dysfunction and atherosclerosis\&nbsp;in mice. Aging 8:1064-1082. https://doi.org/10.18632/aging.100975

Yuan F, Xu ZM, Lu LY, Nie H, Ding J, Ying WH, Tian HL (2016) SIRT2 inhibition exacerbates neuroinflammation and blood-brain barrier disruption in experimental traumatic brain injury by enhancing NF- $\kappa \mathrm{B}$ p65 acetylation and activation. J Neurochem 136:581-593. https://doi.org/ 10.1111/jnc. 13423

Zaza G, Granata S, Caletti C, Signorini L, Stallone G, Lupo A (2018) mTOR inhibition role in cellular mechanisms. Transplantation 102:S3-Ss16. https://doi.org/10.1097/tp. 0000000000001806

Zhang G et al (2013) Hypothalamic programming of systemic ageing involving IKK- $\beta, \mathrm{NF}-\kappa \mathrm{B}$ and GnRH. Nature 497:211-216. https://doi.org/10.1038/nature12143

Zhang W et al (2017) NSCs promote hippocampal neurogenesis, metabolic changes and synaptogenesis in APP/ PS1\&nbsp;transgenic mice . Hippocampus 27:1250-1263. https://doi.org/10.1002/hipo.22794

Zhang LF, Yu XL, Ji M, Liu SY, Wu XL, Wang YJ, Liu RT (2018) Resveratrol alleviates motor and cognitive deficits and neuropathology in the A53T $\alpha$-synuclein mouse model of Parkinson's disease. Food Funct 9:6414-6426. https:// doi.org/10.1039/c8fo00964c

Zhang P et al (2019) Senolytic therapy alleviates A $\beta$-associated oligodendrocyte progenitor cell senescence and cognitive deficits in an Alzheimer's disease model. Nat Neurosci 22:719-728. https://doi.org/10.1038/s41593-019-0372-9

Zhu Y et al (2015) The Achilles' heel of senescent cells: from transcriptome to senolytic drugs. Aging Cell 14:644-658. https://doi.org/10.1111/acel.12344

Zhu Y et al (2016) Identification of a novel senolytic agent, navitoclax, targeting the Bcl-2 family of anti-apoptotic factors. Aging Cell 15:428-435. https://doi.org/10.1111/ acel.12445

Zhu Y et al (2017) New agents that target senescent cells: the flavone, fisetin, and the BCL-X(L) inhibitors, A1331852 and A1155463. Aging 9:955-963. https://doi.org/10. 18632/aging.101202

Zhu X, Yang J, Zhu W, Yin X, Yang B, Wei Y, Guo X (2018) Combination of berberine with resveratrol improves the lipid-lowering efficacy. Int J Mol Sci. https://doi.org/10. 3390/ijms19123903

Zhu Y, Liu X, Ding X, Wang F, Geng X (2019) Telomere and its role in the aging pathways: telomere shortening\&nbsp;cell senescence mitochondria dysfunction. Biogerontology 20:1-16. https://doi.org/10.1007/s10522-018-9769-1

Publisher's note Springer Nature remains neutral with regard to jurisdictional claims in published maps and institutional affiliations. 